\title{
Influence of micrometeorological features on coastal boundary layer aerosol characteristics at the tropical station, Trivandrum
}

\author{
K PARAMESWARAN \\ Space Physics Laboratory, Vikram Sarabhai Space Centre, Trivandrum 695 022, India.
}

\begin{abstract}
Characteristics of aerosols in the Atmospheric Boundary Layer (ABL) obtained from a bistatic CW lidar at Trivandrum for the last one decade are used to investigate the role of ABL micrometeorological processes in controlling the altitude distribution and size spectrum. The altitude structure of number density shows three distinct zones depending on the prevailing boundary layer feature; viz, the well-mixed region, entertainment region and upper mixing region. In the lower altitudes vertical mixing is very strong (the well-mixed region) the upper limit of which is defined as aerosol-mixing height, is closely associated with the low level inversion. The aerosol mixing height generally lies in the range 150 to $400 \mathrm{~m}$ showing a strong dependence on the vertical eddy mixing processes in ABL. Above this altitude, the number density decreases almost exponentially with increase in altitude with a scale height of $0.5-1.5 \mathrm{~km}$. The aerosol mixing height is closely associated with the height of the Thermal Internal Boundary Layer (TIBL). Sea-spray aerosols generated as a result of the interaction of surface wind with sea surface forms an important component of mixing region aerosols at this location. This component shows a non-linear dependence on wind speed. On an average, depending on the season, the mixing region contributes about $10-30 \%$ of the columnar aerosol optical depth (AOD) at $0.5 \mu \mathrm{m}$ wavelength. A long term increasing trend $(\sim 2.8 \%$ per year $)$ is observed in mixing region AOD from 1989 to 1997. A study on the development of the aerosols in the nocturnal mixing region shows that the convectively driven daytime altitude structure continues to persist for about $4-5 \mathrm{hrs}$. after the sunset and thereafter the altitude structure is governed by vertical structure of horizontal wind. Stratified aerosol layers associated with stratified turbulence is very common during the late night hours.
\end{abstract}

\section{Introduction}

Atmospheric Boundary Layer (ABL) is an important source region for tropospheric aerosols. The physical and chemical properties as well as the number density of these aerosols play a significant role in tropospheric chemistry and regional scale radiative forcing. Characteristics of ABL aerosols strongly depend on the source characteristics and prevailing micro-meteorological processes in this region. Being a coastal station, the experiment site encounters a systematic diurnal change in the ABL circulation pattern. During the day the prevailing surface wind is sea-breeze (sea-breeze circulation, SBC), which onsets around 0930IST in the morning. The SBC becomes strong around 1430IST and then weakens. Soon after the sunset the SBC becomes very weak and the wind direction slowly reverses to become a seaward flow around 2000IST. While the wind speed during SBC can increase up to $\sim 10-12 \mathrm{~m} / \mathrm{s}$, the land breeze (LBC) in general is weak and is in the range $1-3 \mathrm{~m} / \mathrm{s}$. During the monsoon season, even though the synoptic scale winds overrides this SBC-LBC pattern, on almost all the days the surface level circulation pattern depicts this characteristic feature. The onset time of SBC

Keywords. Boundary layer aerosols; mixing height; mixing region; turbulence; eddy transport; optical depth. 
and LBC shows variation with season (Prakash et al 1993). During the day the sea spray aerosols produced as a result of the interaction of surface wind with water body forms an important source of ABL aerosols. These oceanic aerosols advecting over the continent mixes with the prevailing continental background aerosol system.

At tropics the solar insulation is quite high and shows significant seasonal variability. Soon after the sunrise, the land gets heated up very fast. The prevailing surface wind is land breeze. As the land-sea temperature contrast increases (land becomes warmer), above a threshold level, the sea breeze onsets. Some times this wind reversal is rather smooth, where as on certain occasions the SBC onsets with a frontal activity (Krishnamoorthy et al 1993). In the morning hours as the surface temperature increases, the vertical convection also increases. Convective eddies rising from the surface reaches up to $\sim 1 \mathrm{~km}$. These eddies play a significant role in the vertical transport of aerosols from the surface to higher altitudes in ABL. With the onset of SBC, cool air from the oceanic environment advects over the land modifying the prevailing temperature structure over the coast leading to the formation of a thermally modified internal boundary layer (TIBL), the height of which is around $200 \mathrm{~m}$ (Kunhikrishnan 1990; Kunhikrishnan et al 1990). Onset of TIBL significantly impedes the penetration of eddies above this altitude and the strong ABL mixing gets confined to the region below. These convective eddies play a significant role in the vertical transport of aerosols and thus governing the altitude distribution of atmospheric aerosols and pollutants in this region. The micro-meteorological features of ABL significantly influence the production and dispersion of aerosols in a coastal site. Study of the characteristics of aerosols in ABL at Trivandrum $\left(8.5^{\circ} \mathrm{N}, 77^{\circ} \mathrm{E}\right)$ a low industrialised tropical coastal station is important in this context. The experiment site is a plane terrain about $10 \mathrm{~km}$ north of Trivandrum city located $\sim 500 \mathrm{~m}$ from the coastline which lies along $325-145^{\circ}$ azimuth. Systematic studies on the characteristics of aerosols in ABL have been carried out at Trivandrum since 1985 some of the results are already published (Parameswaran et al 1995; 1997a; 1997b; 1998). A comprehensive report of these characteristics and the association with boundary layer processes is presented in this article using a significantly long period data spanning a period of one decade.

\section{Altitude structure of aerosol number density}

The bistatic lidar system and method of estimating the aerosol number density $(N)$ are described by Parameswaran et al (1984). The system is operated in the early night hours when a near neutral condition prevails in ABL. In estimating the altitude profile of aerosol number density the size distribution and refractive index of ABL aerosols are to be assumed. The aerosol size distribution is assumed to modified power law type (McClatchey et al 1972) with an average size index of 4.5 and the effective aerosol refractive index is assumed to be 1.45 . In principle the size distribution and refractive index can change with relative humidity $(\mathrm{RH})$ even if one assumes that the aerosol composition does not vary significantly from day to day or from season to season. Using the data from angular scatter measurements from a fixed altitude of $190 \mathrm{~m}$ conducted on different days under different $\mathrm{RH}$ conditions it is observed that (Parameswaran and Vijayakumar 1994a) the size index can vary from 3.7 to 4.7. Parameswaran (1996) using the data for a few days spread over four years observed a decrease in size index $(\nu)$ with increase in $\mathrm{RH}(\%)$ following a relation of the form, $\nu=4.6-0.052(\mathrm{RH}$ $-70)$. As the hygroscopic growth of atmospheric aerosols is not significant for RH less than $70 \%$ the size index remains fairly constant for $\mathrm{RH}<70 \%$. However, the above relationship is not an explicit one because the changes in $\nu$ need not be only due to the changes in $\mathrm{RH}$, considering the data-spread of four years. Even with the above relationship, for $70<\mathrm{RH}<80$ the value of $\nu$ lies between 4.1 and 4.6. In the present study a fixed value for the size index is used which can be in error by \pm 0.2 (which is quite small compared to other uncertainties such as system content, aerosol scintillation, refractive index change etc.) provided $\mathrm{RH}$ is less than $80 \%$. It may be noted in this context that the altitude profiles of $N$ obtained using $\mathrm{CW}$ lidar generally confine to this condition $(\mathrm{RH} \leq 80 \%)$.

Even though the sea spray production decreases in the late evening and early night hours (the wind reversal period) because of the relaxation times of ABL (Delage 1974), particles, which are already airborne take significant time to settle down or get redistributed. Thus the altitude profiles observed in the early night hours are closely associated with $\mathrm{ABL}$, processes in the afternoon hours (when the convective activity is high).

Though the individual profiles of $N$ obtained on different days show large variability, the monthly mean or seasonal mean profiles are rather smooth and depict certain systematic features (Parameswaran and Vijayakumar 1994b). Examining this aspect using the data for the period 19891994 it was found (Parameswaran et al 1995) that seasonal mean profiles of $N$ are rather smooth. In the present analysis the entire data for the period 1989 to 1997 are employed and the seasonal mean profiles obtained by averaging the individual daily 


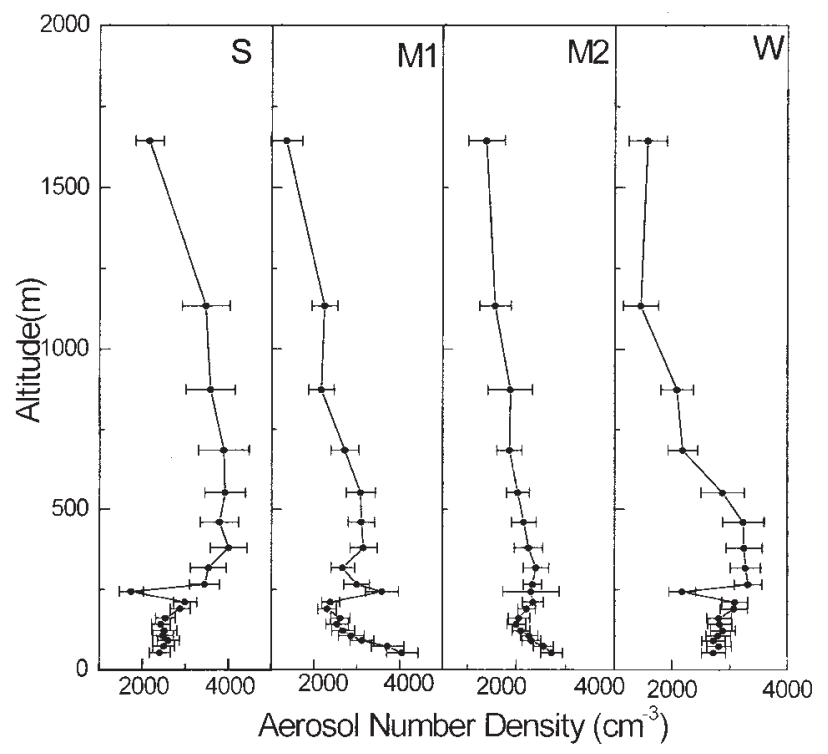

Figure 1. Mean profiles of aerosol number density in the atmospheric mixing region at Trivandrum for different seasons.

profiles in different seasons during this period viz.; Summer (March-May), Monsoon-I (June-August), Monsoon-II (September-November) and Winter (December-February), are presented in figure 1. In this figure S, M1, M2 and $\mathrm{W}$ respectively mark the mean profiles for each of these seasons. In general, these profiles compare favourably with those obtained by averaging the data during the period 1989-94 (Parameswaran et al 1998) indicating that the pattern repeats for the later years also. The march of profile with season is quite evident from this figure. The summer profile is rather smooth with a peak around $400 \mathrm{~m}$ followed by a steady decrease above. The peak around $400 \mathrm{~m}$ is rather broad and the rate of decrease above is small. At this location the surface temperature is maximum (Rekha 2001) during summer months of MarchMay. The ABL convective activity will also be high. Significant amount of aerosols from the surface are transported to higher altitudes, which causes a reduction in $N$ at lower altitudes (as can be seen from figure 1 that $N$ at lower altitudes are relatively low in summer compared to those in the other seasons) and increase at higher altitudes especially between $500-1000 \mathrm{~m}$ compared to other seasons.

During the S-W monsoon period increased washout by monsoon rains reduces the amplitude of the peak $\sim 400 \mathrm{~m}$. This continues and during the second half of monsoon the peak around $400 \mathrm{~m}$ is quite insignificant and the $N$ profile is more or less exponential. With the withdrawal of monsoon from the continent in winter, the rainfall becomes scanty. Though the surface temperatures are low in these winter months, the land is generally dry. Owing to a dry underlying surface the convective

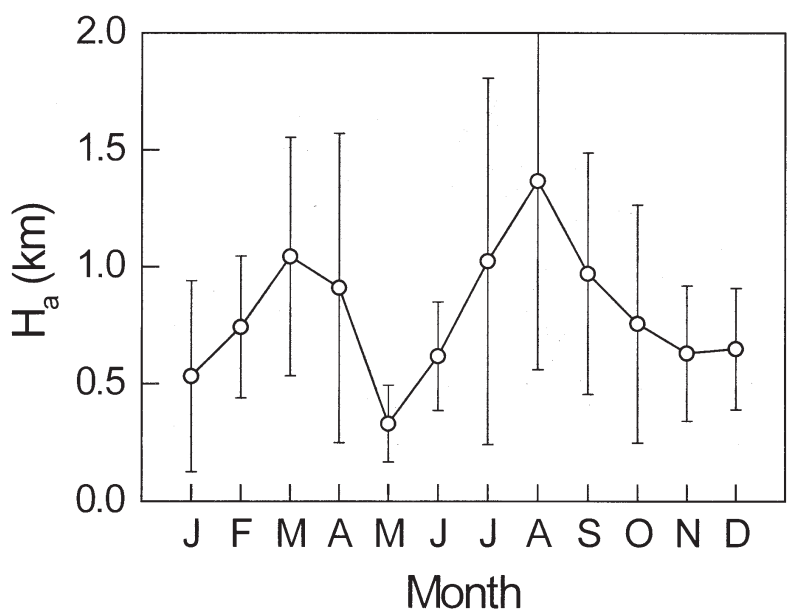

Figure 2. Seasonal variation of mean aerosol scale height $\left(H_{a}\right)$.

activity in ABL increases (though will not be as high as in summer). Associated with this the peak in $N$ around $400 \mathrm{~m}$ starts building up. Thus, from this figure it can be seen that the peak in $\mathrm{N}$ around $400 \mathrm{~m}$ is closely linked with convective activity in ABL.

Another interesting feature observed in the $N$ profiles during the monsoon period is the increase aerosol concentration below $\sim 100 \mathrm{~m}$. After a decrease from $400 \mathrm{~m}$ to $100 \mathrm{~m}, N$ shows an increase with decrease in altitude. The monsoon period is associated with strong westerlies (turning to north-westerly over the Kerala coast with advancing monsoon) from the Arabian Sea over to the main land. The sea will be generally rough and strongly agitated throughout this period. Agitation of sea surface produces abundant sea-spray aerosols. But the land is generally wet and because of the weak convective activity prevailing in ABL during this season, these aerosols remain confined to lower latitudes (unlike the summer period). However, as will be seen later, the vertical mixing during this period is dominated by mechanical turbulence generated by vertical shear of horizontal wind. But as mechanical turbulence is rather discontinuous and not as strong a mechanism for vertical transport as the convective turbulence vertical dispersal of aerosol during the monsoon period is weak. This causes trapping of aerosols produced from sea-spray in lower altitudes. This phenomenon is seen in both the monsoon seasons $M_{1}$ and $M_{2}$. As the surface wind speeds (Parameswaran et al 1998) associated with the second half of the monsoon season, $M_{2}$, are relatively low (the seaspray production also will be less) the increase in $N$ below $100 \mathrm{~m}$ is small during this period.

From figure 1 it can be seen that above $\sim 400 \mathrm{~m}$ the aerosol concentration decreases monotonically with increase in altitude. This decrease in $N$ with altitude is more or less exponential. In analogy to 

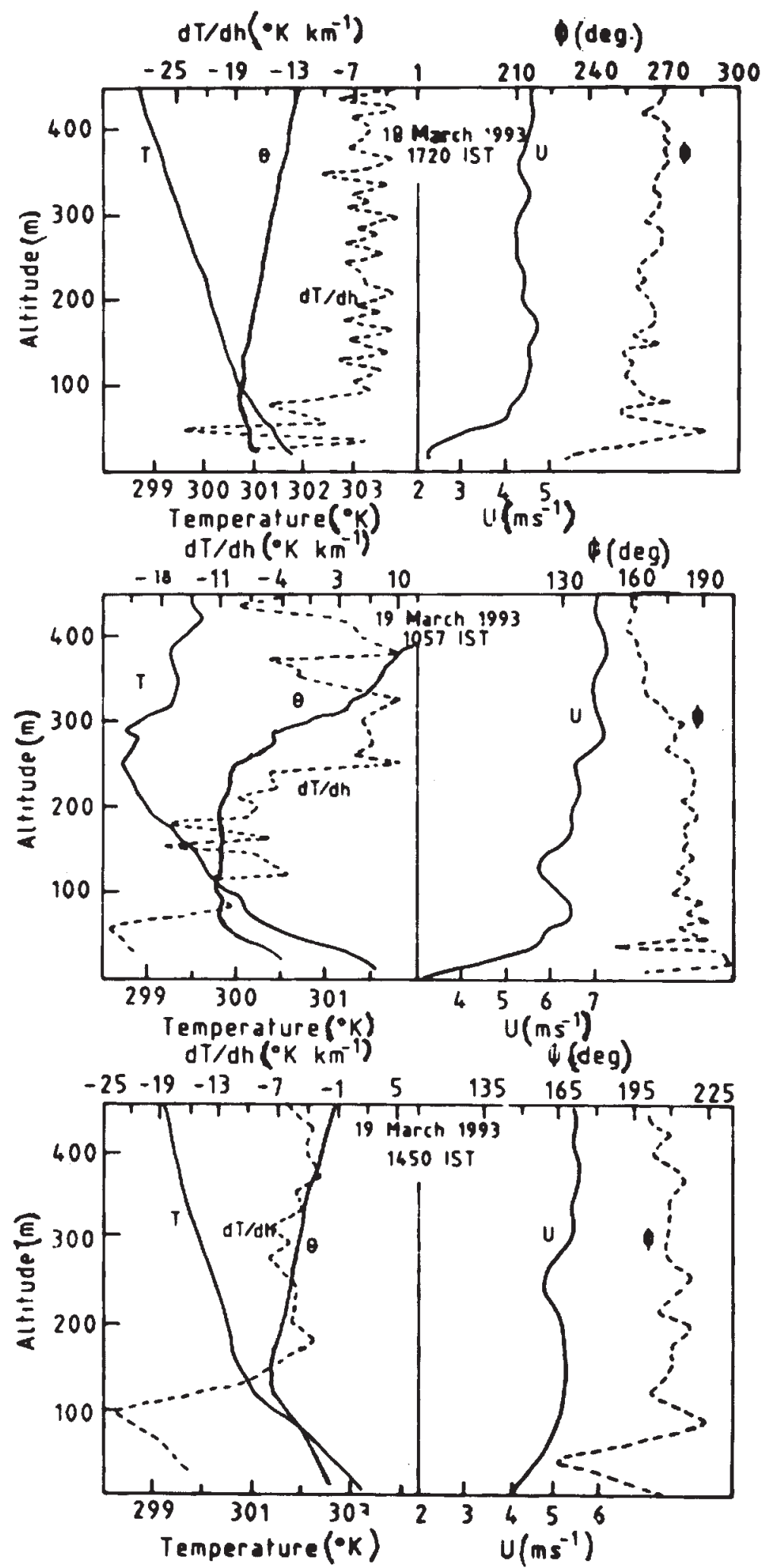

Figure 3(a). Altitude profiles of temperature $(T)$, potential temperature $(\theta)$ temperature gradient $(\mathrm{d} T / \mathrm{d} h)$, wind speed $(U)$ and wind direction $(\phi)$ on 18th March $1993 \sim 1720$ IST, 19th March 19931057 IST and 19th March 19931450 IST, for three typical of ABL conditions obtained from tethersonde soundings. 


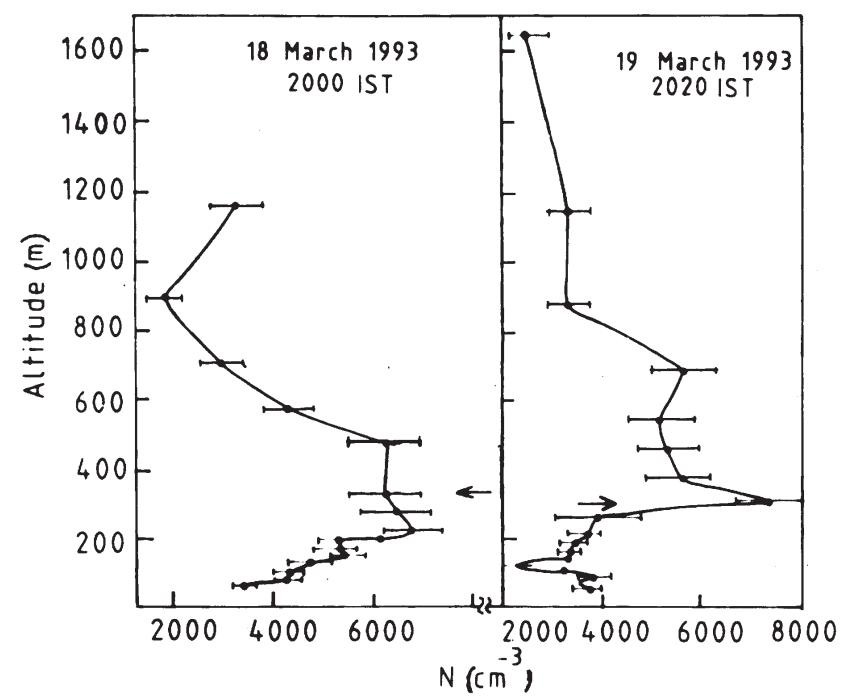

Figure 3(b). Altitude profiles of aerosol number density during the early night hours on 18th and 19th March 1993.

altitude variation of molecular number density in the atmosphere and scale height this decrease in $N$ can also be expressed as a function of altitude with a scale height parameter $H_{a}$. Monthly mean profiles of $N$ in different months during the period 1989-97 have been examined in this context and the aerosol scale heights are estimated by the least square method. It is observed that the aerosols scale height generally is in the range 0.5 to $1.5 \mathrm{~km}$. Figure 2 shows the mean values $H_{a}$ in different months for the period 1989-97, vertical bars representing the standard error. This figure shows that $H_{a}$, in general, is low during May and December and high during summer and S-W monsoon $\left(M_{1}\right)$ periods. Low values of $H_{a}$ are indicative of sharper altitude gradient in $N$ and hence weak vertical mixing. From figure 2 it can be seen that during summer and the S-W monsoon period vertical mixing extends to higher altitudes.

\section{Turbulent diffusion and aerosol mixing height}

Atmospheric boundary layer is the region where vertical transport of surface fluxes like heat, moisture etc. is quite significant. This is accomplished by eddy transport. Eddies generated as a result of surface heating are transported vertically up until the rising air parcel encounters a region having equal ambient density. These eddies are efficient carriers of heat and momentum from the surface to higher altitude in the ABL. In addition to this, these rising air parcels (called convective eddies) also carry aerosol particles from the surface to higher altitudes. The altitude region where eddy transport is significant is referred to as the wellmixed region.
Altitude structure of aerosol number density in the ABL depends on the characteristics of ABL, which can be understood from the altitude profiles of temperature $(T)$ or wind speed $(U)$. It would be sometimes more useful to use the potential temperature $(\theta)$ defined as $\theta=T(1000 / P)^{R / C p}$, where $P$ is the atmospheric pressure in mb, $R$ is the universal gas constant and $C p$ the specific heat at constant pressure for dry air. The altitude profiles of temperature gradient and $\theta$ provide information of the prevailing stability condition in this region. Figure 3(a) shows the altitude structure of $T, \theta, \mathrm{d} T / \mathrm{d} h, U$, and wind direction $\phi$ under three different $\mathrm{ABL}$ conditions obtained using a slow raise balloon on 18th and 19th March 1993. Figure 3(b) shows the altitude profiles of $N$ obtained from CW lidar on these two days during the early night hours. The first frame in figure 3(a) shows the altitude profiles of boundary layer parameters during the early night hours of 18th March 1993 when a near neutral condition prevails in ABL. The second frame in figure 3(a) shows the altitude profiles in the convective boundary layer before the onset of SBC (and formation of TIBL). ABL height is around $300 \mathrm{~m}$ as seen from the altitude profile of $\theta$ (Parameswaran et al 1997b). The third frame in figure 3(a) shows the altitude structure of ABL parameters in the afternoon hours (fully developed convective boundary layer with TIBL) where the ABL height decreases to $\sim 200 \mathrm{~m}$. The altitude profiles of $N$ in figure 3(b) show that the peak in $N$ appears around $300 \mathrm{~m}$, which is the altitude of the prevailing daytime ABL. For the present case the region up to $\sim 300 \mathrm{~m}$ is the well-mixed region and the aerosol mixing height is $\sim 300 \mathrm{~m}$. More details on the estimation of aerosol mixing height and the seasonal variation will be discussed in subsequent sections.

Vertical transport of convective eddies can be traced using sodar (Kunhikrishnan 1990). The convective eddies constitute air parcels whose densities are lower than the density of surrounding medium. These eddies are good scatters for acoustic waves. Acoustic energy scattered by these irregularities is used for tracing the altitude extent of eddy transport in sodar. These convective eddies are referred to as thermals (or plumes) and the altitude extent up to which the sodar signals are observed is referred to as the thermal plume height which is a measure of the altitude extent of the well-mixed region.

Figure 4 shows photographs of sodar facsimile for four days in different months during the year 1990, showing the thermal plume structure. Figure 5 shows the altitude profiles of $N$ obtained using lidar in the early night hours on these days. In figure $4 Y$-axis shows the altitude (in $\mathrm{m}$ ) and $X$ axis the time in IST. Intensity of trace is propor- 


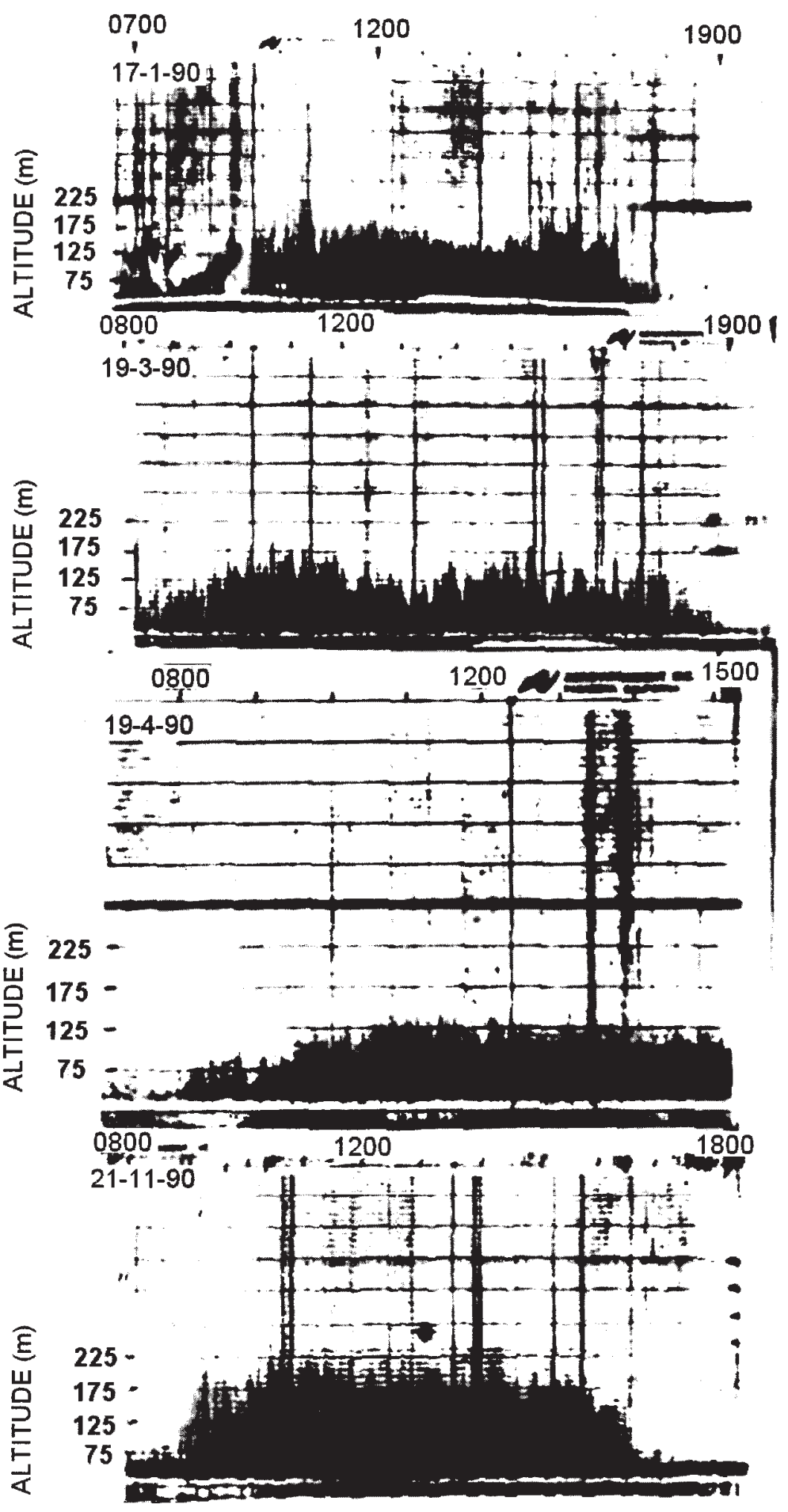

Figure 4. Sodar facsimile showing the thermal plumes on four different days in the year 1990. 


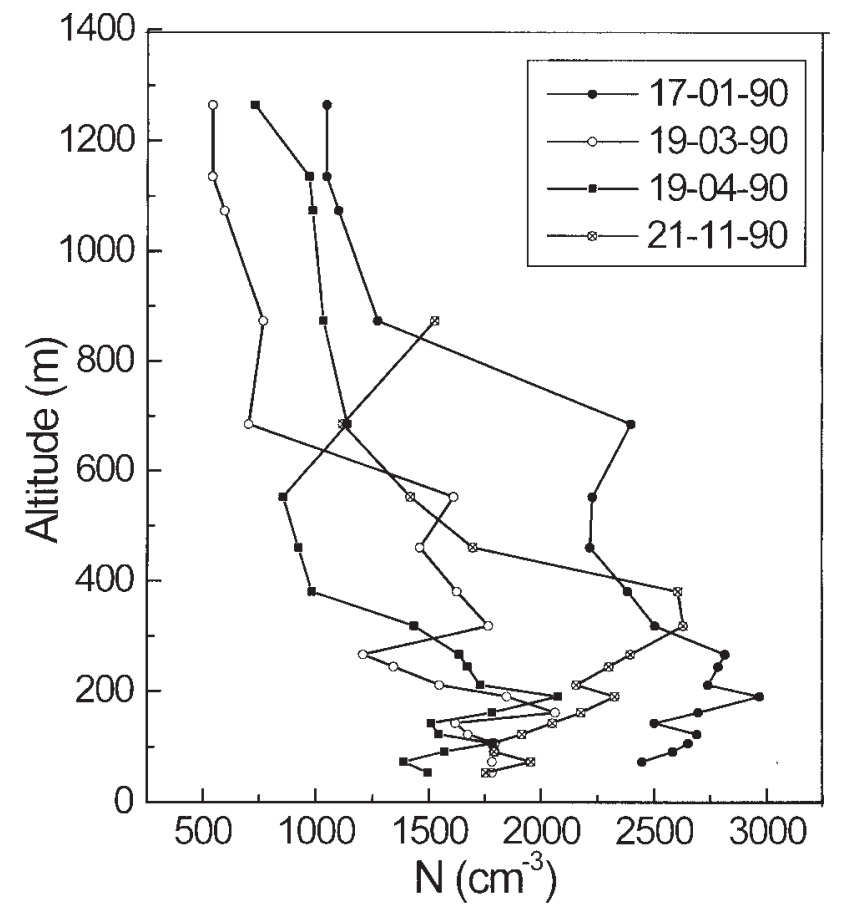

Figure 5. Altitude profiles of aerosol number density on four different days in 1990, for which the daytime thermal plume structures are presented in figure 4 .

tional to received acoustic power. From figure 4 it can be seen that soon after the sunrise thermals start building up fast and become strong. The altitude extent of the plume is $\sim 180 \mathrm{~m}$ on 17 th January 1994 which decreases to $\sim 100 \mathrm{~m}$ during noon, after the onset of TIBL, and again increases in the evening hours. These plumes become weak in the evening hours. The same feature is observed for 19th March 1990 also where the plume heights are generally larger, extending up to $\sim 180 \mathrm{~m}$ in the morning and afternoon hours. In April (19th April, 1990) plume heights extend only up to $120 \mathrm{~m}$ and the dip around noon is not well pronounced. On 21st November 1990 the plume heights extend to higher altitudes exceeding $180 \mathrm{~m}$. From the above it can be seen that soon after the onset of a breeze and the subsequent formation of TIBL the thermals are suppressed (because of low level inversion) and the plume height decreases slightly. The TIBL becomes strong in the afternoon hour (when sea breeze is maximum) 1430 IST the height of TIBL is (and plume height) lower than that in the morning hours. Towards evening, TIBL becomes weak and so is the case for plume intensity. But the vertical extend slightly increases. Soon after the sunset, the land cools down very fast and eddy production ceases quickly and the thermal plumes disappear fast.

It would be worth in this context to examine the altitude profile of aerosol number density on these days shown in figure 5 and their association with boundary layer features. The aerosol con- centration in the lower altitude is highest for the profiles on 17th January 1990 and it decreases in March-April (19.03.1990 and 19.04.1990 profiles) and again increases in November (27.11.1990). In addition to this change in $N$, the profile for 17th January 1990 shows a prominent peak $\sim 200 \mathrm{~m}$. A profile for 19th March 1990 shows two peaks one prominent peak $\sim 200 \mathrm{~m}$ (which is seen for 19th April 1990 also) and a broad peak $\sim 400 \mathrm{~m}$. The profile for 21st November 1990 shows a prominent peak $\sim 300 \mathrm{~m}$. It may also be seen from figure 5 that the vertical gradient in $N$ is a maximum just below the peak. Within the internal boundary layer (region below the peak) the gradient is small and $N$ do not show any decreasing trend. Above the peak the aerosol concentration decreases monotonically with increase in altitude. These peaks in $N$ compare favourably with the thermal plume heights on the respective days, shown in figure 4 but for being slightly higher. Sasano et al (1982) have examined the altitude profile $N$ in the mixing region along with low level radiosonde observation and found that the peak in $N$ (called as the top aerosol layer) forms just above the mixed layer. They attributed this to a relatively stable condition prevailing just above the inversion height. From figures 4 and 5 also it can be seen that the peak in (or the aerosol layer) forms just above the internal boundary layer.

It can be seen from the above that in the lower altitudes the atmosphere is fairly well mixed and the peak in $N$ appears just above the altitude of temperature inversion. The region below the aerosol peak is significantly dominated by eddy mixing which is referred to as the well-mixed region. The height up to which aerosols remain fairly well mixed is referred to the aerosol mixing height. Even though this mixing height compares favourably with the height of temperature inversion (or the plume height) they are not exactly the same (Coulter 1979) The solar plume height $\left(h_{p}\right)$ will be a lower estimate because of the fact that at higher altitude the convective eddies are rather weak (low refractive index contrast) thereby reducing the backscattered acoustic power. These sodar signals from higher altitudes will not be strong enough to be registered by the recorder. But as far as aerosols are concerned the mixing height estimated will be larger than the inversion height because some of the eddies will be strong enough to penetrate the inversion and deposit the aerosols above.

\section{Mixing region and aerosol mixing height}

Coulter (1979) defined the mixing height as the height where the temperature lapse rate first becomes sub-adiabatic. The mixing height from 


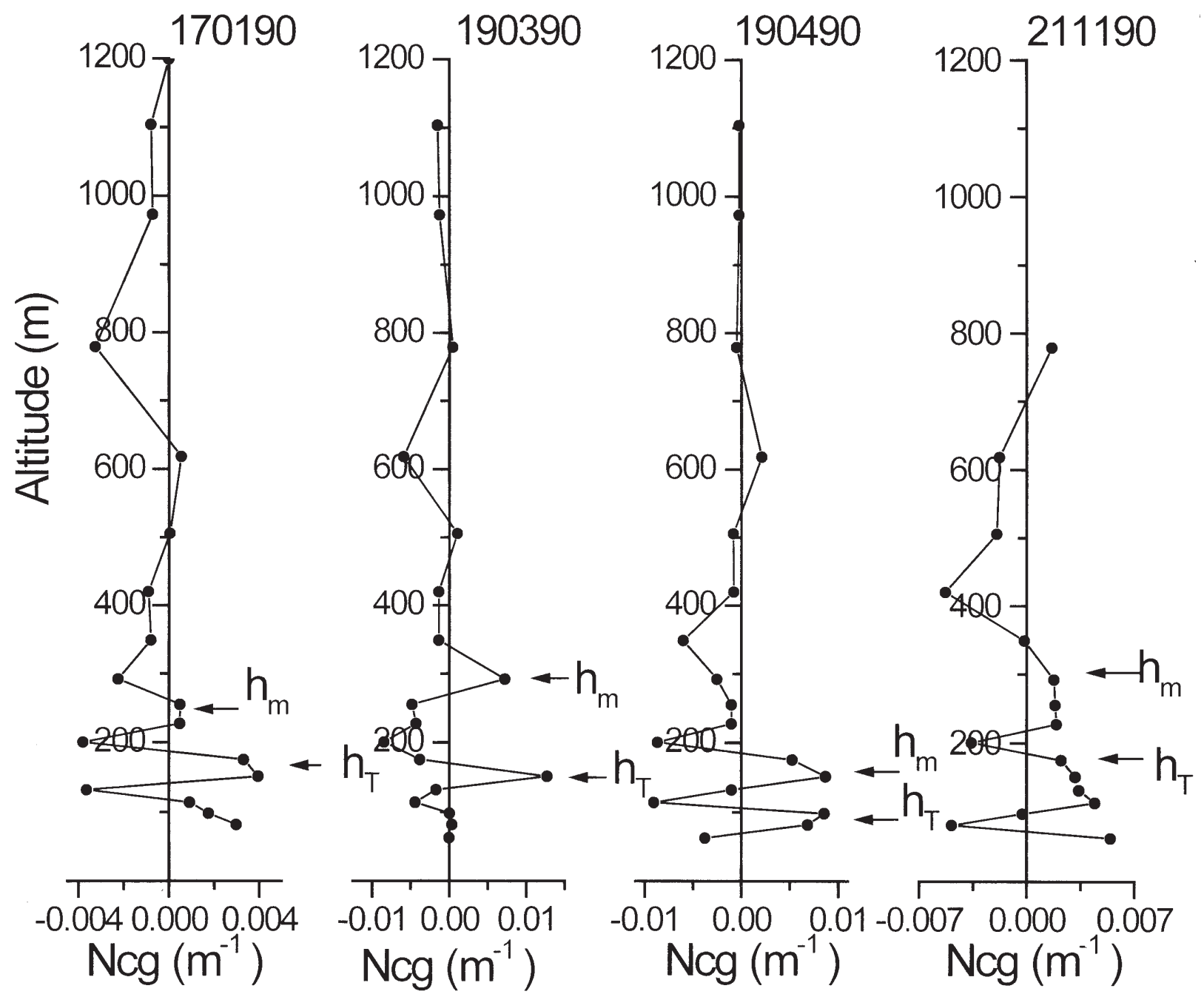

Figure 6. Altitude profiles of normalized concentration gradient (Ncg) on 17.01.90, 19.07.90, 19.04.90 and 21.11.90, for which the profiles of $N$ are presented in figure 5 .

aerosol profiles is defined as the height where there is a sudden decrease in particle concentration. However, the mixing heights from temperature profile and aerosol number density need not be the same. Sasano et al (1982) used normalised concentration gradient $(\mathrm{Ncg})$ defined as $\mathrm{Ncg}=$ $(\delta N / \delta h) / N$; a parameter to determine the aerosol mixing height. As this parameter normalized to ambient aerosol number density $(N)$ the uncertainty in the absolute value of $N$ due to the uncertainty in the lidar calibration constant etc. will not affect the Ncg profile. The mixing height is identified from the altitude profile of Ncg as the altitude above which it continues to remain negative. This method of obtaining the mixing height $\left(h_{m}\right)$ has widely been used to study the evolution of daytime mixed layer (Devara et al 1993, 1998; Parameswaran et al 1997a). Based on the profiles of $N$ at Trivandrum, Parameswaran et al. (1997a) have described the method of estimating $h_{m}$ and also pointed out that the value of $\mathrm{Ncg}$ will be highest at a lower altitude below $h_{m}$, defined as $h_{T}$ which usu- ally match with the altitude of TIBL at this station (Rajeev and Parameswaran 1995; Parameswaran et al 1997b). Figure 6 shows the altitude profile of Ncg obtained for the aerosol number density profile shown in figure 5 . On some days the altitude of $h_{m}$ and $h_{T}$ can coincide. The altitudes of $h_{T}$ and $h_{m}$ as defined above are marked in this figure. Values of $h_{T}$ for 17-1-90, 19-3-90, 19-4-90 and 21-11-90 are respectively $170,150,100$ and $180 \mathrm{~m}$ respectively and those of $h_{m}$ are 255, 290, 180 and $290 \mathrm{~m}$ respectively. It can be seen that the altitude of $h_{T}$ matches fairly well with the height of TIBL (or plume height) observed in the afternoon period (figure 3) with the condition that the plume height will be an under estimate of TIBL. Following the definition of Sasano et al (1982) the altitude region below $h_{m}$ is referred to as the well-mixed region. The region from $h_{m}$ to $\sim 700 \mathrm{~m}$ where $N$ shows a sharp decrease with increase in altitude is referred to as the entrainment region (through which aerosols in the well mixed region intrudes into the upper region). Above the entrainment 


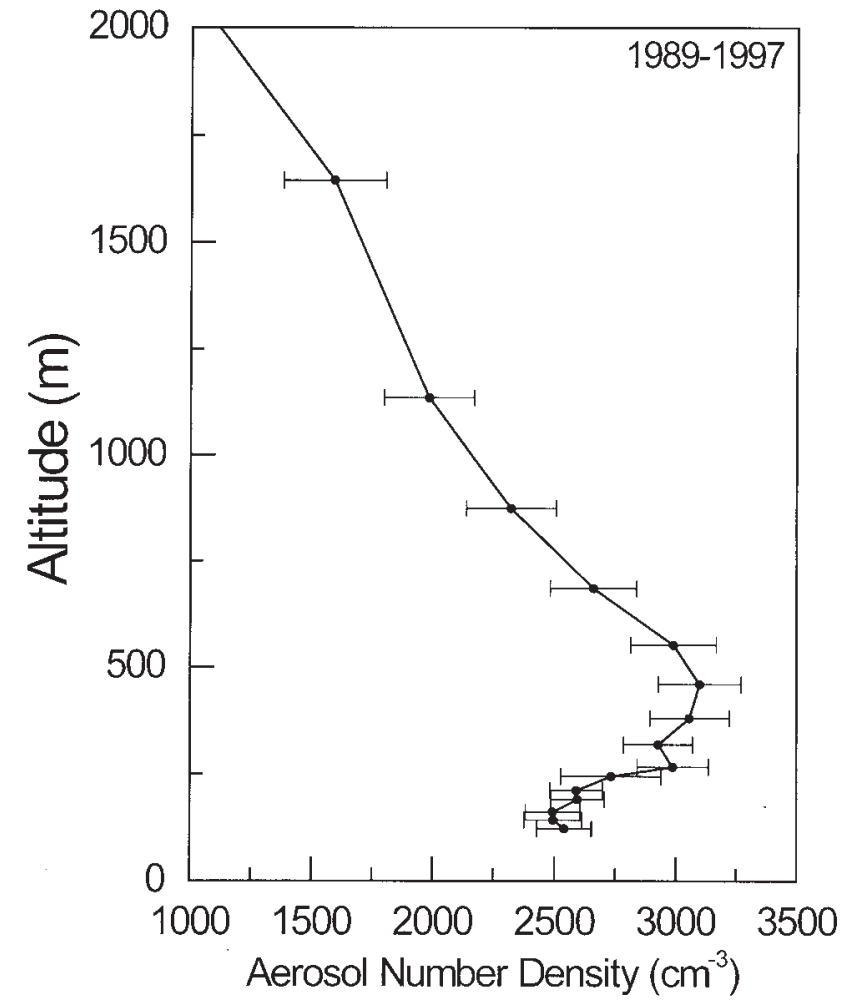

Figure 7. The mean profile of aerosol number density in the mixing region obtained by averaging all the daily profiles during the period 1989-1997.

region the aerosol concentration decreases rather slowly with increase in altitude. Thus the influence of ABL micrometeorological features influences the aerosol concentration up to an altitude of $\sim 1 \mathrm{~km}$, and above this altitude this effect is rather small. Figure 7 shows a mean profile of $N$ obtained by averaging the entire daily profiles during the period 1989-97. This averaging however smooths out all (day to day, seasonal, inter annual etc.) temporal variation and presents a typical model profile for altitudes below $1.5 \mathrm{~km}$. Examining this profile based on the above-described features, the aerosol mixing height is $\sim 400 \mathrm{~m}$ and the region below this is the well-mixed region. The altitude region from $400 \mathrm{~m}$ to $600 \mathrm{~m}$ is the entrainment region and the region above $600 \mathrm{~m}$ is the upper region. In this context, it would be worth examining the structure of "mixing region" as far as aerosols are concerned. As in the case of ABL, the upper limit of the mixing region cannot be sharply defined and varies with the definition adopted (for the case of boundary layer, the upper limit is defined at a different context depending on the topic of interest as low level inversion, elevated inversion, trade wind inversion etc.) Strictly speaking, the term mixing region can be used to refer the altitude region up to the trade wind inversion level (Kaimal and Finnigan 1994; SenGupta and Radhika Ramachandran 1998), though we are limiting the upper level of mixing region to $\sim 1.1 \mathrm{~km}$ in the present case partly also because of the fact that only a limited number of $N$ profiles ( $<\sim 40 \%$ ) will extend beyond $1.2 \mathrm{~km}$. One can also define the mixing region in terms of aerosol scale height, as the region below the height where the concentration falls by $e^{-1}$, which can go up to $1.5 \mathrm{~km}$. Thus for the present study the region up to $\sim 1.1 \mathrm{~km}$ is referred to broadly as the "mixing region" which has the structures like well mixed region, entrainment region and top mixing region.

\section{Seasonal variation of aerosol mixing height and its association with convective activity and wind shear}

Aerosol mixing height $\left(h_{m}\right)$ shows significant day-to-day variability depending on the prevailing meteorological conditions, in the atmospheric boundary layer. It shows a strong dependence on convective activity in ABL. (The thermal plume height, $h_{p}$, is a good representative index for the strength of ABL convective activity). Another important factor governing the vertical mixing in ABL is the mechanical mixing induced by wind shear. Exton et al (1985) have examined this aspect based on data obtained at the coastal site South Uist $\left(56.4^{\circ} \mathrm{N}\right)$ and observed that the aerosol mixing height is governed by the stronger of the two mixing processes. The association of $h_{m}$ on convective and mechanical mixings in $A B L$ has been examined using the data obtained at Trivandrum.

Mixing heights have been obtained from the altitude profiles of $N$ for different days by examining the altitude profile of $\mathrm{Ncg}$ as described above. They generally lie in the range 150 to $400 \mathrm{~m}$. Monthly mean values of $h_{m}$ thus obtained for different months for the year 1990 are presented in figure 8(a). Figure 8(b) shows the month-to-month variation of average $h_{p}$ as reported by Kunhikrishnan et al (1990) obtained from sodar facsimile. From figure 8(a) and 8(b) it can be seen that $h_{m}$ is maximum during the dry month of March and November as well as during the S-W monsoon period (June-July). The maxima in $h_{m}$ during the dry months correspond fairly with the maximum in $h_{p}$ (figure $8 \mathrm{~b}$ ) indicating that these peaks are caused by increased convective activity in ABL. But during the monsoon period, the land is wet and convective activity is low. Because of this $h_{p}$ also is low. The monsoon peak in $h_{m}$ cannot be attributed to convective activity. But as reported by Rao (1976) the wind shear is quite high during the S-W monsoon period. These strong wind shears can generate mechanical turbulences leading to increased vertical mixing. To examine this aspect the mean wind shears at $60 \mathrm{~m}$ level is estimated for different 


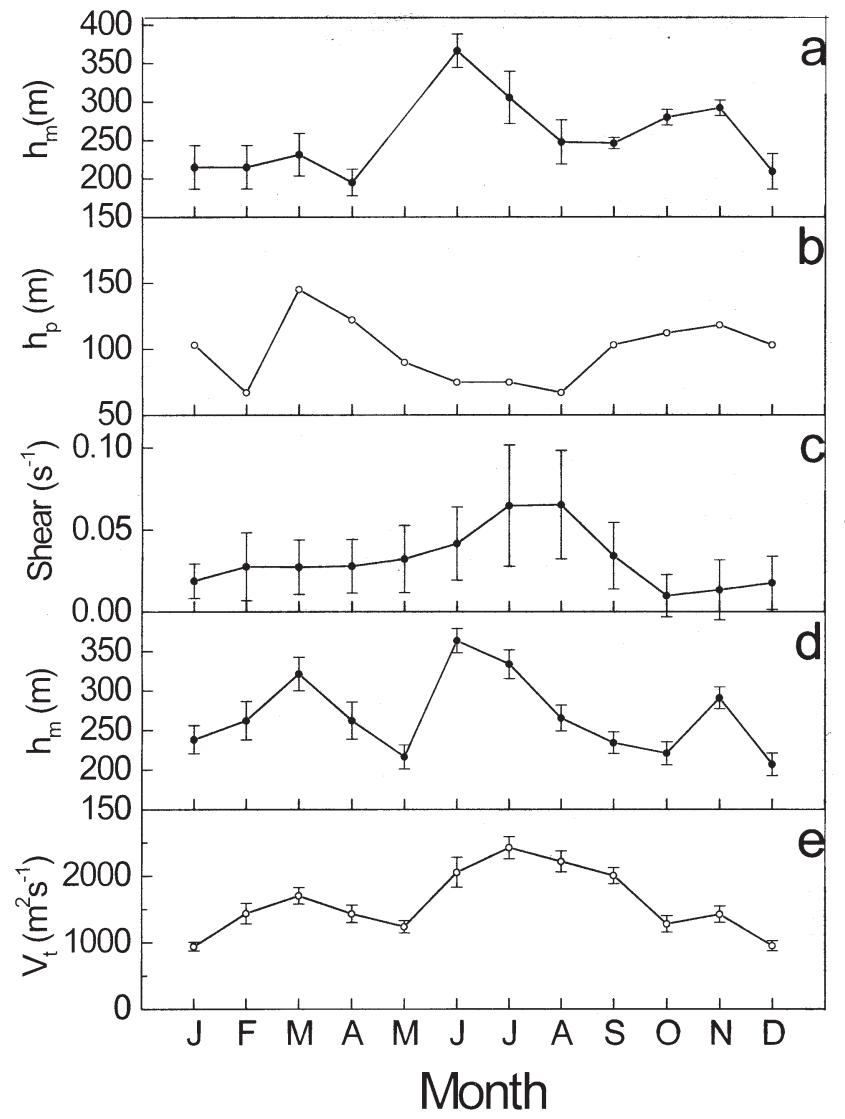

Figure 8. Month-to-month variation of aerosol mixing height $\left(h_{m}\right)$ in the year 1990 along with the sodar plume height $h_{p}$, wind shear averaged for 1989-92, mixing height averaged for 1989-97 and ventilation coefficient $(V t)$.

months using the wind data recorded at the experimental site (Parameswaran et al 1997a). The average wind shear in different months for the period 1989-92 is presented in figure 8(c), which shows a prominent peak during the June-July months. This corresponds fairly well with the peak in $h_{m}$ during the S-W monsoon period. It should be remembered in this context that the mechanical mixing is discontinuous in altitude and hence is not an efficient carrier for aerosols. Thus, even though the height of the well-mixed region (or the mixing height) increases during the $\mathrm{S}-\mathrm{W}$ monsoon period due to increased mechanical mixing, the vertical transport of aerosols through this mechanism is not very effective. This aspect is borne out by the low values of Ncg observed (Parameswaran et al 1997a) near $h_{m}$. Hence, during this period the aerosol produced near the surface mostly remains confined to altitudes below $100 \mathrm{~m}$ (the maximum limit of $h_{p}$ during this period) even though $h_{m}$ as defined from $\mathrm{Ncg}$ increases to $250 \mathrm{~m}$ or more. Seasonal pattern of $h_{m}$ shown in figure 8(a) repeats from year to year the average value of which is presented in figure $8(d)$. It would be worth in this context to examine the internal boundary layer height estimated from frequency weighted power spectra of horizontal wind, $6 \mathrm{~km}$ inland from the present coastal site (Sunil 1997), which varies in the range $250-450 \mathrm{~m}$ depending on the season. This compares favourably with the value of $h_{m}$ estimated from lidar profiles of $N$ using the above method and is higher than $h_{p}$ obtained from sodar.

Dispersion of pollutants in the atmosphere is governed by the mixing height. Larger values of $h_{m}$ generally provide more volume of atmosphere for the dispersion of pollutants, which effectively reduces the concentration (stagnation) of pollutants near the surface. Dispersion of pollutants is also influenced by wind speed. Large wind speeds can disperse the pollutants faster thereby reducing the concentration. The atmospheric ventilation coefficient, which is defined as the product of $h_{m}$ and the mean wind speed in the mixing region, is used to assess the pollution potential at a place (Devara and Raj 1993; Devara et al 1998). The atmospheric ventilation coefficient $\left(V_{t}\right)$ estimated from $h_{m}$ and mean wind speed around $60 \mathrm{~m}$ (taken as representative for mean in mixing region) is presented in figure $8(\mathrm{e})$. This shows a sharp peak during the S-W monsoon period and low in May and October. The peak during the summer month is rather small. Conversely at an inland station like Pune (Devara and Raj 1993) the ventilation coefficient is low during the winter and monsoon periods and high during summer. Low value of this parameter indicates a less efficient dispersion of pollutants. Thus, the pollution potential at Trivandrum is quite high in May and October where as at Pune the pollution potential is high during the winter months (Devara and Raj 1993). Compared to Pune, in general, the pollution potential is high at the coastal station Trivandrum in the absence of other removal mechanisms like wet removal and washout. The onset of TIBL during the day significantly suppresses the vertical eddy transport there by reducing the mixing height, which is one of the main reasons to this increased pollution potential in the coastal region.

\section{Wind speed dependence}

Figure 9 shows a typical plot of the aerosol number density at eight different altitudes in $\mathrm{ABL}$ with surface wind speed obtained from the data obtained during the period 1989-94. The aerosol number density at each altitude during this period are grouped in wind speed intervals of $1 \mathrm{~m} / \mathrm{s}$ and averaged. The vertical bars represent the standard error. This figure indicates that aerosol number density in the atmospheric mixing region follows a non-linear dependence on wind speed (SBC). In analogy to earlier works (Exton et al 1985) this 

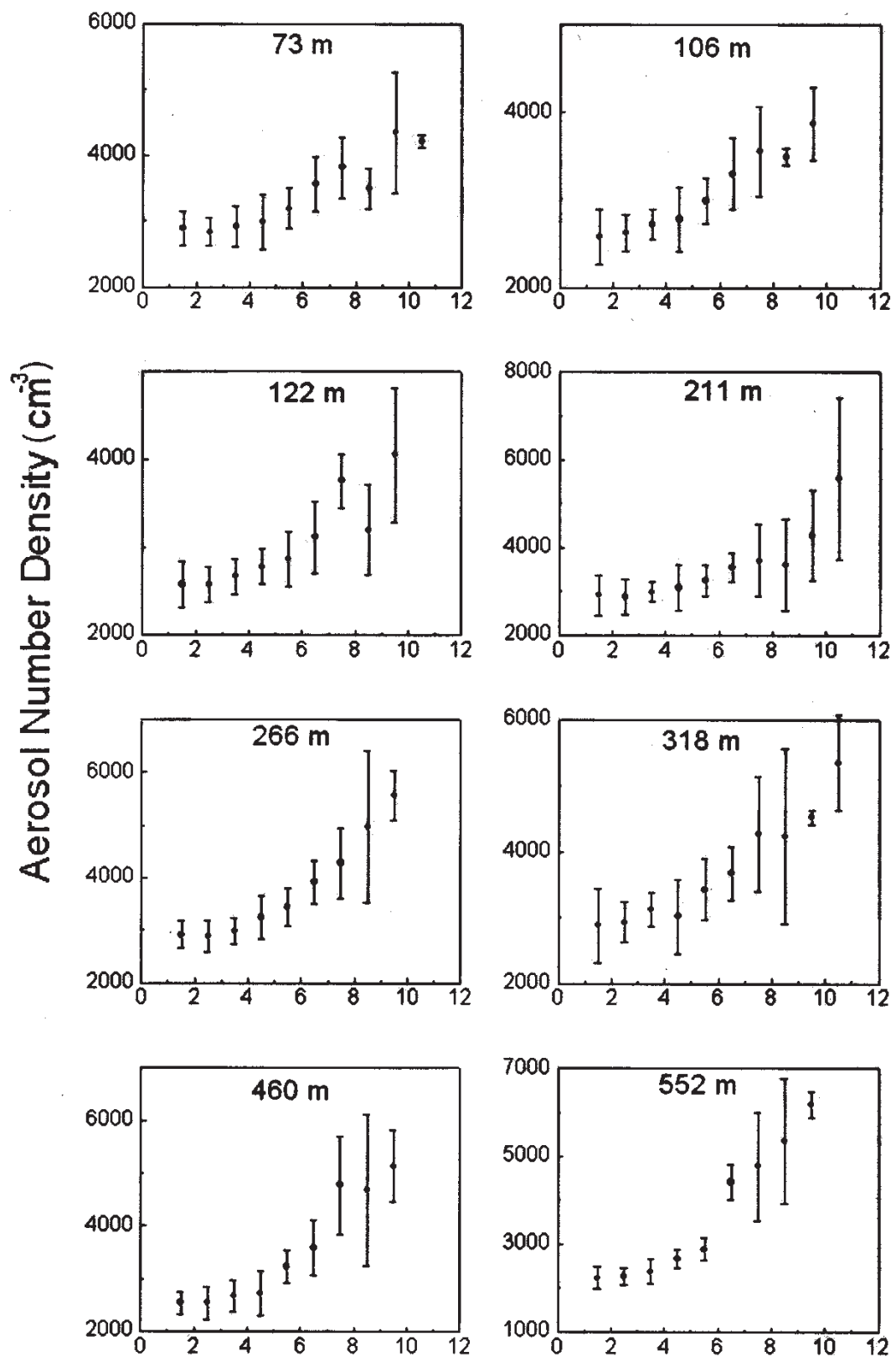

Wind Speed (m/sec)

Figure 9. Variation of aerosol number density at different altitudes in ABL with surface wind speed.

variation can be represented by an exponential function $N=N_{0} e^{b u}$, where $U$ is the surface wind speed. The value of $b$ is $\sim 0.1 \mathrm{~S} / \mathrm{m}$. In this relationship the rate of change in $N$ with respect to $U$ is proportional to $N$ itself. Such an analytical form for $N$ is true when the prevailing aerosol number is redistributed by wind speed, similar to the case of hydrostatic equation representing pressure variation in atmosphere under the influence of gravity. But in practice the wind contribution is that component generated from water surface because of wind pressure which depends on its speed. This is added to the prevailing background aerosol system. The source strength of wind-contributed compo- nent is negligible for $U<3 \mathrm{~m} / \mathrm{s}$ (Monahan et al 1983). The wind contribution to $N$ is also a nonlinear function of $U$. Thus a power law is more appropriate for representing this non-linear variation in which case $N$ can be represented as $N=$ $N_{b}+c U^{d}$ where $N_{b}$ is the background component (which is independent of $U$ ) and $c U^{d}$ is the real time wind contributed component. The wind dependent component of $N$ decreases with decrease in wind speed and becomes zero as $U \rightarrow 0$. The altitude structure of $N_{b}, c$ and $d$ are discussed in detail by Vijayakumar et al (1998). The values of $d$ is $\sim 2.94$ in the well-mixed region and increases to 3.5 above this region. As described above the vertical 


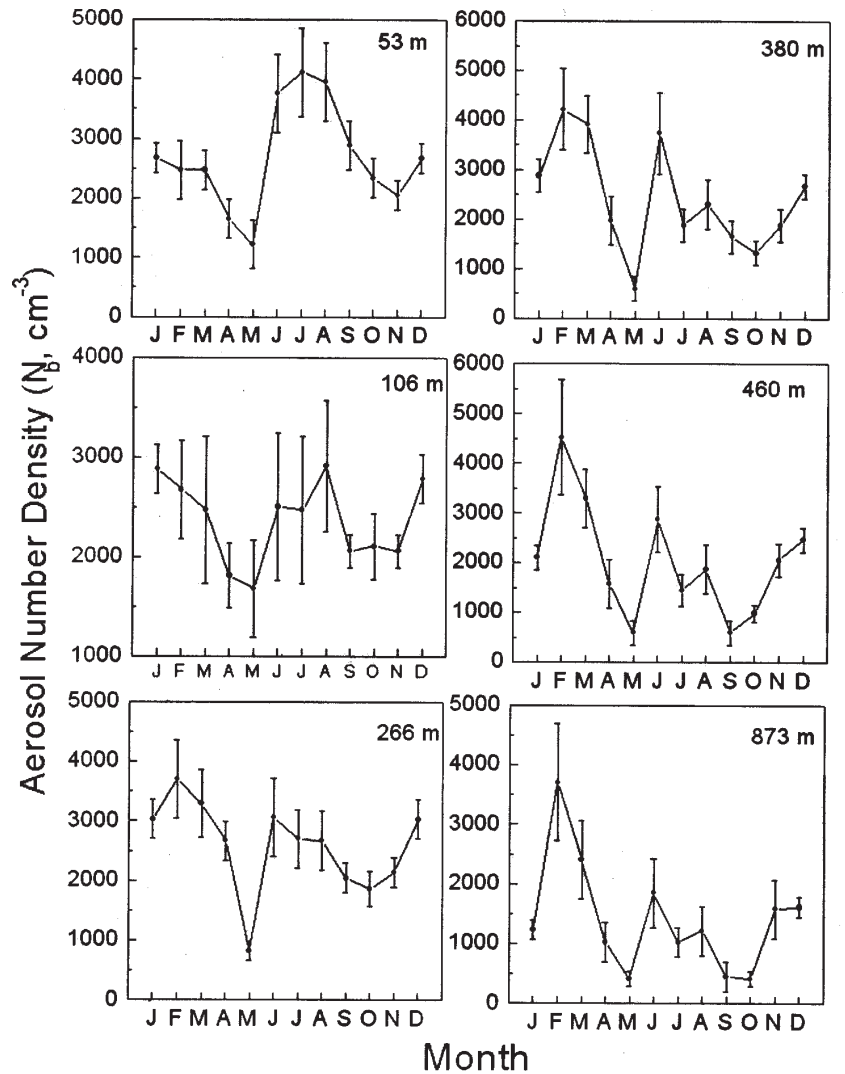

Figure 10. Month-to-month variation of $N_{b}$ at different altitudes.

mixing in the mixing region strongly depends on the prevailing dynamics of ABL, the seasonal pattern of $N_{b}$ should be different at different altitudes. Figure 10 shows the month-to-month variation of $N_{b}$ at different altitudes averaged for the period of analysis. In general, the seasonal variation of $N_{b}$ shows two maximum one during the winter and the other during the S-W monsoon period. In the lower altitudes, $h<100 \mathrm{~m}$, the monsoon peak is quite prominent. Around 100-200 m, both these peaks are comparable and at altitudes above $400 \mathrm{~m}$, the winter peak dominates. On examining the associated physical processes it can be seen that during the winter months sea breeze is low and the land is dry. The production of continental aerosols will be significant during the period. During S-W monsoon period land is wet and wind speed is high. So the contribution from sea-spray aerosols will be dominant. Thus, the winter peak can be identified as due to the increase in the background continental aerosols transported to higher altitudes in the mixing region due to increased vertical mixing prevailing in the dry months, which becomes increasingly prominent at higher altitudes. The monsoon peak in $N$ is due to aged oceanic aerosols related to general increase in the average wind speed level, mainly confined to the lower altitudes because of the fact that the vertical transport by convection

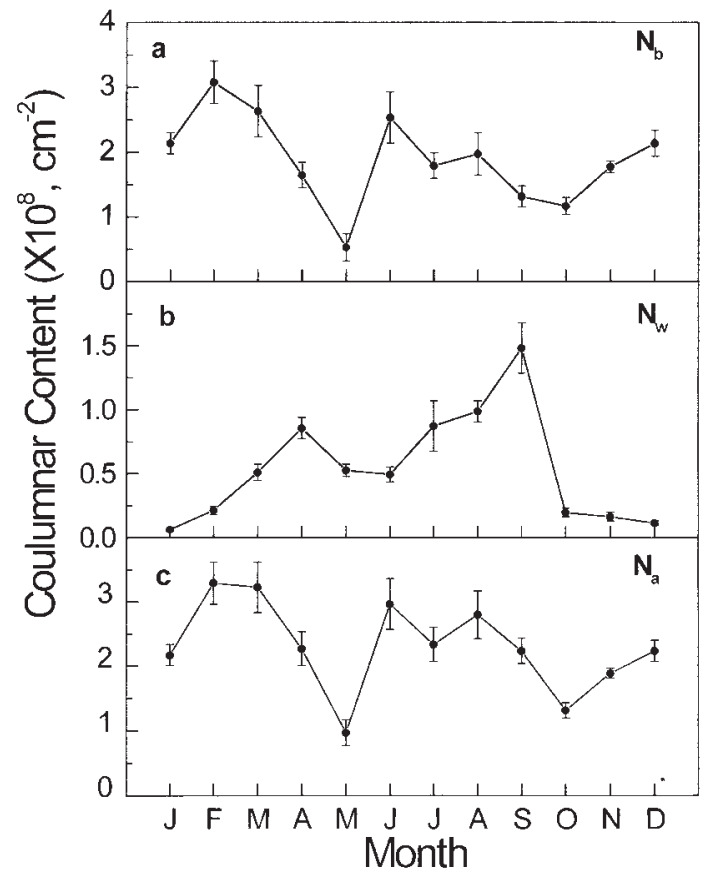

Figure 11. Month-to-month variation of columnar aerosol content $\left(N_{a}\right)$, columnar content of wind contributed component $\left(N_{w}\right)$ and columnar content of the background component $\left(N_{b}\right)$.

is less effective during this period. The prominence of this peak decreases with the increase in altitude.

To examine the relative importance of background and wind contributed components in mixing region aerosol content, the columnar content of $N_{b}$ and $N_{w}\left(=c U^{d}\right)$ are evaluated up to $1 \mathrm{~km}$ for different days and the monthly mean values are presented in figure 11. This figure shows that the wind contribution is insignificant during the winter month and maximum during the S-W monsoon month of June-August. During this period about $30 \%$ of aerosol content in the first $1 \mathrm{~km}$ region is contributed by sea spray aerosols. The background component is low during this period. During the winter months this component is high.

\section{Seasonal and long term trends}

The altitude profile of $N$ shows systematic variation with season depending on the prevailing source-sink characteristics and active distribution mechanisms. In addition, the increase in anthropogenic activity increases the aerosol loadings in the atmosphere, which modifies the characteristics of the natural aerosol system. Systematic data spanning for a period of ten years have been used to study the seasonal and long-term trends in the altitude structure and columnar loadings. Monthly mean profiles of $N$ are used for this purpose.

Figure 12 shows the contour plot of $N$ at different altitudes for the period 1989 to 1997. The 


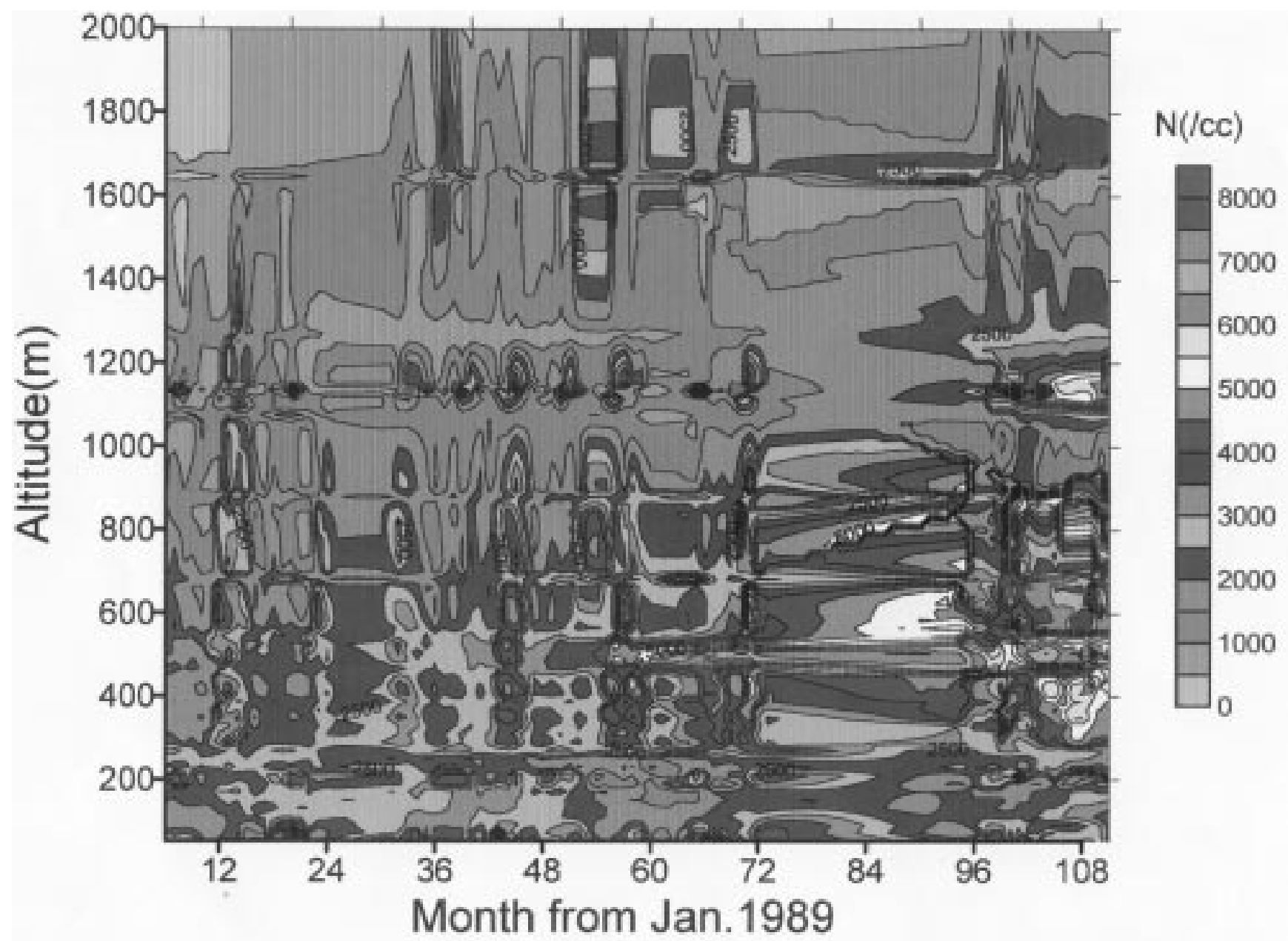

Figure 12. A contour plot of aerosol number densities at different altitudes for the period 1989-97 obtained from monthly mean profiles of $N$.

$X$-axis shows the Julian month starting from January 1989. The mixing height can be seen in this figure as the height close to the surface where $N$ is maximum and shows a steady decrease above. The seasonal and inter annual variation in aerosol concentration at different altitude regions are clearly observable in this figure during the period 198994. In the rest of the period the seasonal pattern is not very clear because of data gaps during the period 1995-97. In addition to this seasonal and inter annual variation a significant increasing trend can also be observed from 1989 to 1997 which is quite prominent at lower altitudes. The aerosol concentration in the well-mixed region also shows an increasing trend.

Aerosol number density in the lower altitudes is significantly governed by the characteristics of local sources and sinks and strength of vertical eddy transport. Even though the vertical transport of aerosols from the surface to higher altitudes is significant in the entire troposphere (Parameswaran et al 1993), at higher altitudes (say, above the trade wind inversion level of $\sim 2 \mathrm{~km}$ ) the horizontal transport is quite significant. In this altitude region the aerosol characteristics are also influenced by synoptic scale circulation (aerosols from nearby regions will also influence the local aerosols characteristics). Vertical dispersion of aerosols by eddies, which is very strong in the well-mixed region, does not remain confined to lower altitudes. Depending on the strength of these eddies some aerosols are injected above the mixing height. Once they are injected above the well-mixed region, this can be lifted up through the weaker eddies prevailing in this region. However, the strength of these eddies decreases with increase in altitude. From the altitude profiles of $N$ (figure 1) and seasonal variation of $N_{b}$ at different altitudes (figure 11) it can be seen that the features observed in lower altitudes extend up to $\sim 1 \mathrm{~km}$. A cross correlation analysis of aerosol concentration at different altitude regions with that in the lowest $200 \mathrm{~km}$ has shown that the correlation decreases with increase in altitude and is $\sim 0.6$ around $1 \mathrm{~km}$. From these factors based on features cited in section 4 for the following analysis of seasonal and long-term trends the altitude region $0-1.1 \mathrm{~km}$ is taken as the mixing region (which is characterised by season- 
ally varying well-mixed, entrainment and upper region.)

In order to examine the seasonal and long-term trends in aerosol loading and compare with other measurements it will be worth examining the variation in aerosol optical depth. The mixing region aerosol optical depth $\left(\tau_{m}\right)$ at the lidar wavelength of $0.5145 \mu \mathrm{m}$ is estimated from the monthly mean profiles of $N$ by integrating it up to $1.1 \mathrm{~km}$ and multiplying with the effective extinction cross section $\left(3.04 \times 10^{-4} \mathrm{~cm}^{2}\right)$ applicable for a mean aerosol size index (4.5) and aerosol refractive index 1.45 (Parameswaran et al 1998). The columnar aerosol optical depth $\tau_{c}$ (Krishnamoorthy et al 1991) at $0.5 \mu \mathrm{m}$ wavelength obtained from the solar radiometer is used along with this data to study the influence of mixing region aerosols on the observed columnar optical depth.

Figure 13 shows the month-to-month variation of $\tau_{m}$ and $\tau_{c}$ averaged for the period 1989 to 1997 along with the difference between $\tau_{c}$ and $\tau_{m}$ and the ratio $\tau_{m} / \tau_{c}$ representing respectively the seasonal variation of aerosol optical depth above the mixing region and relative contribution of mixing region to columnar optical depth respectively. As the present analysis deals with the background aerosol system the volcanically disturbed period (due to the eruption of Mt. Pinatubo in 1991) June 1991 to June 1993 is excluded for $\tau_{c}$ (and hence for $\tau_{c}-\tau_{m}$ and $\tau_{m} / \tau_{c}$ also). The seasonal variation of $\tau_{m}$ shows a sharp peak in February followed by a broad peak during the S-W monsoon period. The former peak can be attributed to increased aerosol loading from the continent and the latter to increase contribution of sea-spray aerosols. As seen from figure 11 the wind contribution to mixing region aerosol concentration is significant from April to September. The columnar aerosol optical depth shows a maximum during summer (March-April) and minimum during the $\mathrm{S}-\mathrm{W}$ monsoon period. The increase in $\tau_{c}$ during summer can be attributed to increase loading in troposphere (as seen from figure 13c) either by increased vertical transport (figure 1) or due to in situ production through Gas to Particle Conversion (GPC) process. The efficiency of GPC increases with increase in temperature, which is the case for summer season at tropics. Figure 13(c) shows two prominent peaks one in summer and the other in winter. The contribution of mixing region to columnar aerosol optical depth is maximum (30\%) in February and July. The vertical dispersion is generally weak in these months and a significant amount of aerosols remain confirmed to lower altitudes. In summer the vertical mixing is very strong which reduces the contribution of $\tau_{m}$ to the columnar optical depth to $10 \%$.

During the monsoon period wet removal is very strong in troposphere. Sea-spray aerosols produced

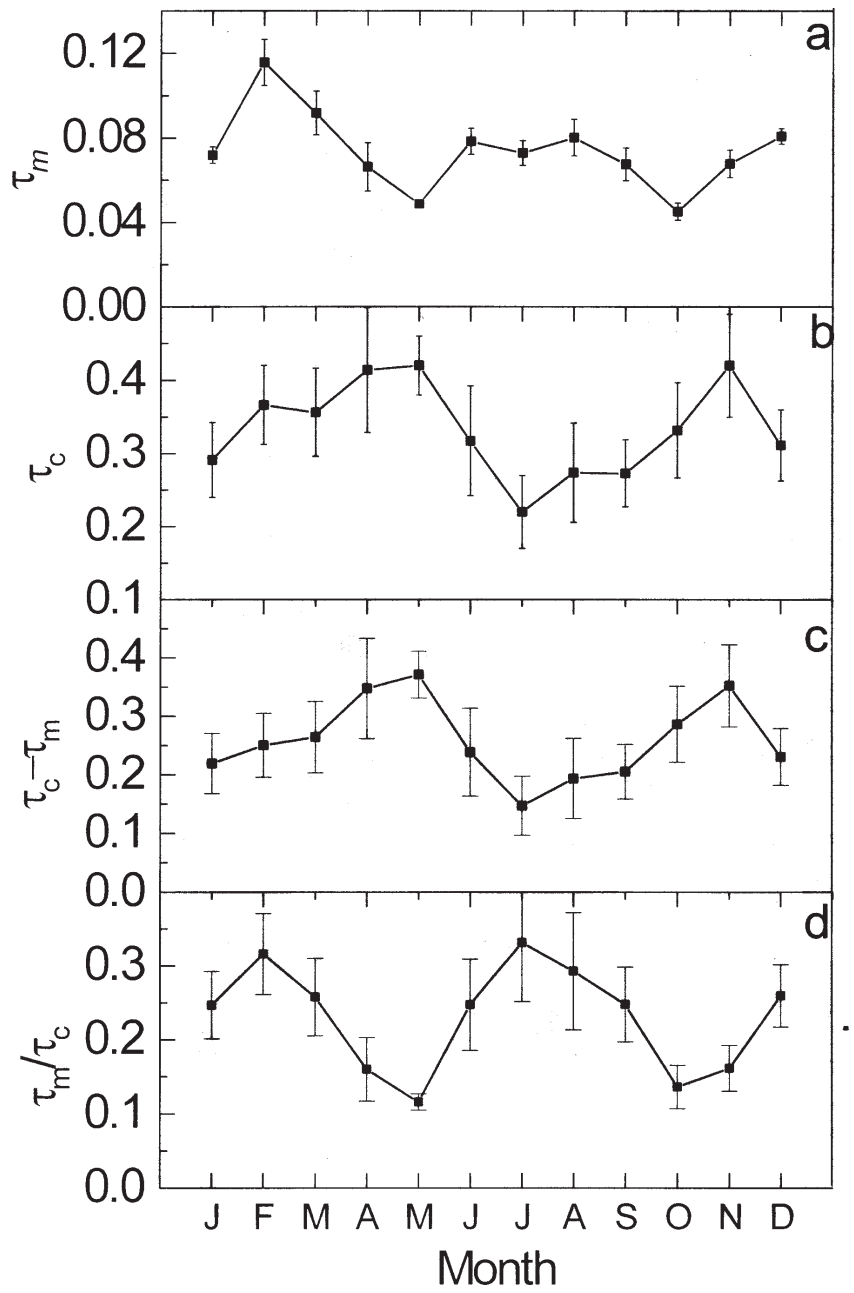

Figure 13. Month to month variations of aerosol optical depth at $0.5 \mu \mathrm{m}$ wavelengths (a), that in the mixing region up to $1.1 \mathrm{~km}, \tau_{m},(\mathbf{b})$, in the entire column of atmosphere, $\tau_{c}$, (c), for the region above $1.1 \mathrm{~km}$ and (d) contribution of mixing region to columnar optical depth (e).

during this period are confined to the lower altitudes. This increases the relative contribution of $\tau_{m}$ to $\tau_{c}$. In October aerosol production near the surface is low. But there is an increase in $\tau_{c}$ (from that during the monsoon period), which would have been contributed by advecting aerosols aloft, governed by synoptic scale atmosphere features.

In addition to this seasonal variation, $\tau_{m}$ and $\tau_{c}$ show a small increasing trend from 1989 to 1997 (Parameswaran et al 1998). In order to examine this aspect the seasonal and annual variations in $\tau_{m}$ and $\tau_{c}$ at $\tau_{m}-\tau_{c}$ are suppressed by taking a running mean for 13 months. These values of $\left(\tau_{m}\right)_{13},\left(\tau_{c}\right)_{13}$ and $\left(\tau_{c}-\tau_{m}\right)_{13}$ are presented in figure 14 . The scatter plot represents the respective running mean value for the centred month of the running mean window. To quantify the trend a regression line is established for each of the above scatter plots. This regression line is also presented in figure 14 . The slope of this line provides the linear gradient from the reference value in 1989 . The rate of 


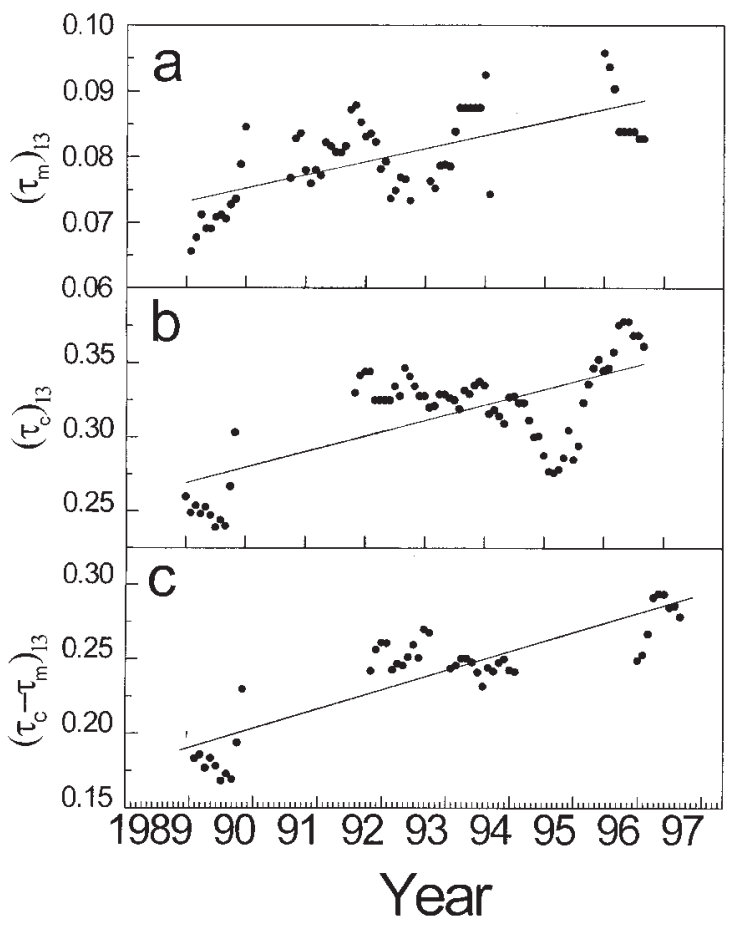

Figure 14. Long term trends in $\tau_{m}, \tau_{c}$ and $\tau_{c}-\tau_{m}$ at $0.5 \mu \mathrm{m}$ wavelength for the period 1989-1997.

increase is $\sim 2.8 \%$ per year for $\tau_{m}, \sim 4 \%$ for per year from $\tau_{c}$ and $\sim 7 \%$ for $\left(\tau_{c}-\tau_{m}\right)$. The increasing trend is more for $\tau_{c}$ and is significantly contributed by the increase in aerosol loading in the upper troposphere. This analysis thus indicates that the observed increasing trend in $\tau_{c}$ is not a locally confirmed feature but more synoptic in nature.

It would be worth in this context to examine the trends in aerosol loading observed at different locations over the Indian continent. Using a systematic long-term measurement of aerosol number density profile in ABL using a CW lidar Devara et al (1997) reported a similar increasing trend in the columnar aerosol content from 1986-1996. A perusal of columnar aerosol optical depth $\left(\tau_{c}\right)$ data at Trivandrum, Mysore and Visakhapatnam for the period 1989-1999 (Krishnamoorthy et al 1999), the three IGBP (Indian Geosphere Biosphere Program) Network stations where a long term data base is available, also shows a similar increasing trend with differing magnitudes. From this it is evident that the increasing trend in aerosol loading observed at Trivandrum is not an isolated feature and forms a part of the overall increase in aerosol loading over the entire continent. A study on the spectral behaviour of these trends at Trivandrum reveals that the increasing trend in $\tau_{c}$ is more pronounced for shorter wavelengths $(\leq 0.6 \mu \mathrm{m})$. Figure 15 shows a plot of 13-month running mean of monthly mean of $\tau_{c}$ at three different wavelengths $0.4,0.6,0.8$ and $1.02 \mu \mathrm{m}$ (other than $0.5 \mu \mathrm{m}$ which is presented in figure 14) depicting this feature. This suggests

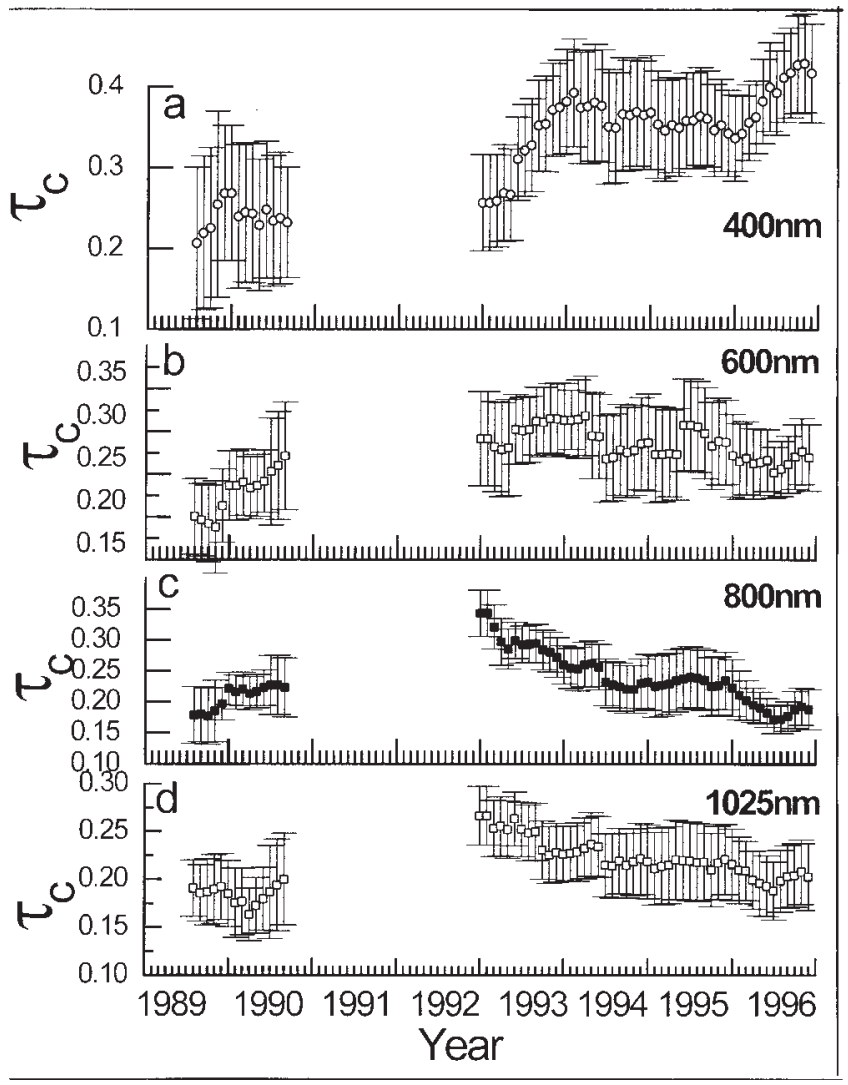

Figure 15. Long term trends in columnar aerosol optical depth at four wavelengths $0.4,0.6,0.8$ and $1.02 \mu \mathrm{m}$ obtained from solar radiometer.

that the increasing trend in aerosol loading is more pronounced for smaller size particles, (possibly the sub micron ones) which are mostly of anthropogenic origin. At the higher wavelengths $(0.8 \mu \mathrm{m}$ to $1.02 \mu \mathrm{m}) \tau_{c}$ shows a small decreasing trend from 1989 to 1997. This study thus reveals that there is a general preferred increasing trend for the sub micron aerosol loading over the Indian continent due to anthropogenic impact for the last one decade.

This result has important implications in the context of the recent Indian Ocean Experiment (INDOEX) which was aimed at the advection of continental aerosols in the pristine oceanic environment during the winter season when the prevailing wind over the continent is north easterly (Parameswaran et al 2001). These observations indicated that the Indian subcontinent is one of the major sources of aerosols (Rajeev et al 2000) advecting over the Indian Ocean. The increasing trend in aerosol loading during the last one decade over the continent as observed above is quite significant. This indicates an increasing trend for the aerosol flux over the oceanic environment from the adjacent continent. Atmospheric aerosols play a significant role in the radiation balance (Charlson et al 1992) of the earth atmospheric system leading to a 
negative forcing (decrease in solar energy reaches the surface) provided the particles are of the nonabsorbing type. This situation becomes more complex when absorbing type aerosols are present, depending on the case whether they are internally or externally mixed. Accordingly the single scatter albedo and scattering phase function gets modified. A significant component of the observed increase in aerosol loading is in troposphere, which can play a major role (Coakley et al 1983; Schwartz 1996) in the regional scale radiative forcing. This in turn can influence the climate system on a regional scale and could also alter the monsoon rain pattern over the continent (Lal et al 1995).

\section{Contribution of well-mixed region}

A significant component of mixing region aerosol is contained in the well-mixed region. The altitude extent of this region is governed by $h_{m}$, which depends on vertical eddy transport in ABL. The aerosol concentration in this region also depends on the source strength. Hence, the aerosol content (or the aerosol optical depth) in the wellmixed region will depend upon both these factors. It will be interesting in this context to examine the contribution of this region to the mixing region aerosol optical depth. The aerosol optical depth in the well-mixed region $\left(\tau_{s}\right)$ is estimated as above by integrating the $N$ profile up to $h_{m}$, for that month, and multiplying it with the effective aerosol extinction cross-section. Monthly mean profiles of $N$ and $h_{m}$ (Rekha 2001) for different months in the period of analysis are used for this purpose. Figure 16(a) shows the month-to-month variation of average $\tau_{s}$, obtained by averaging the individual $\tau_{s}$ values in the same month for different years during the period 1989-97. Vertical bars in figure 16 represent the standard errors. Minimum value of $\tau_{s}$ is encountered in April, May and October months. The monsoon peak is very broad. Figure 16(b) shows the ratio $\tau_{s} / \tau_{m}$, representing the contribution of well-mixed region to mixing region aerosol optical depth. Contribution of $\tau_{s}$ to $\tau_{c}$ can be obtained by multiplying $\tau_{m} / \tau_{c}$ (in figure $13 \mathrm{~d})$ with $\tau_{s} / \tau_{m}$. This ratio $\left(\tau_{s} / \tau_{m}\right)$ varies in the range 0.22 to 0.4 with a sharp minimum in February and May and a broad maximum during the period June to October. This pattern strongly suggests the important contribution of sea-spray to $\tau_{m}$. Figure 16(c) shows the 13-month running mean of $\tau_{s}$ for the period 1989-97. No discernable trend in $\tau_{s}$ is observable as in the case of $\tau_{m}$ and $\tau_{c}$. But a well pronounced decadal variation with a minimum in 1993-94 period is observable. This pattern matches fairly well with the long-term pattern of monthly total rainfall and average wind

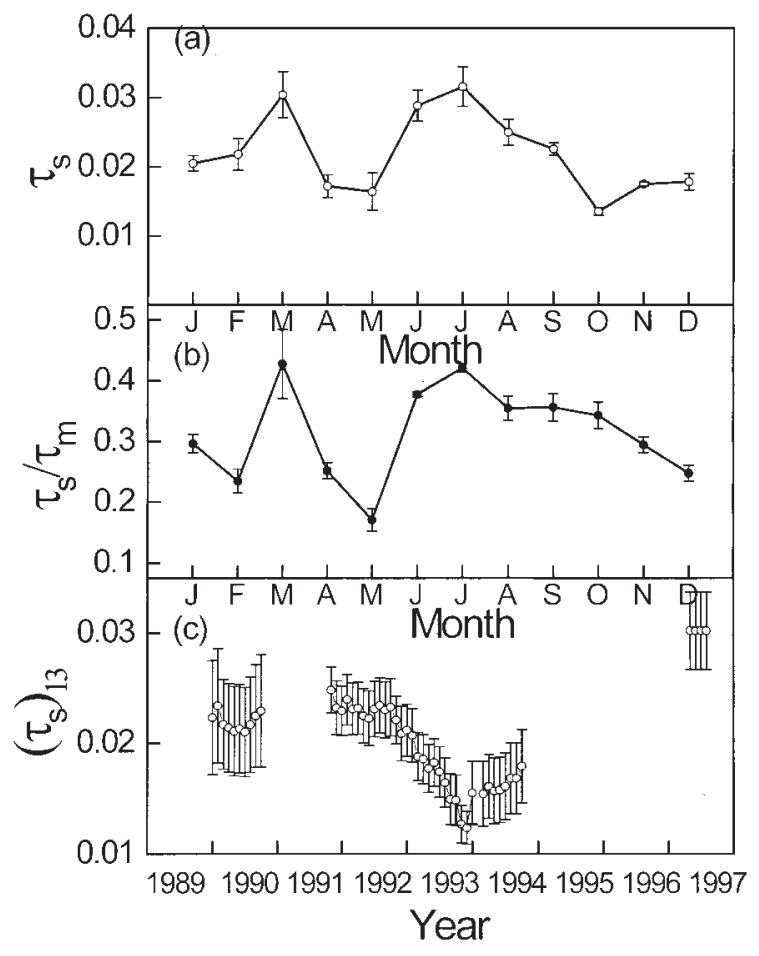

Figure 16. Month-to-month variation of columnar aerosol optical depth in the well-mixed region, $\tau_{s},(\mathbf{a})$, contribution of well-mixed region to mixing region aerosol optical depth (b), and variation of $\left(\tau_{s}\right)_{13}$ during the period 1989-97 (c).

speed (SBC) at 1430 IST (Rekha 2001) on this site. Both these parameters show a minimum around 1993-94, which also brings out the close association between wind speed and rainfall pattern at this location. This study thus brings out the fact that the aerosol optical depth in the well-mixed region is significantly governed by local source strength and no long-term increasing trend is observable, may be due to the dominance of the decadal variation.

\section{Development of nocturnal mixing region}

The convectively driven daytime mixing region aerosol number density profile continues to persist for a few hours after the sunset and can change its features later according to the prevailing wind profile. The development of nocturnal structures in $N$ profile has been studied in detail using the altitude profiles obtained at regular intervals of $1 \mathrm{hr}$ throughout the night (Parameswaran et al 1997b). More details regarding the evolution of nocturnal ABL aerosol number density profile, premidnight and post-midnight contrast and possible association with the spatial extent of daytime sea breeze cell etc are explained in detail elsewhere (Parameswaran et al 1997b). Only a summary of the important features observed in the nocturnal aerosol number density profile is presented in this 
September 19,1990
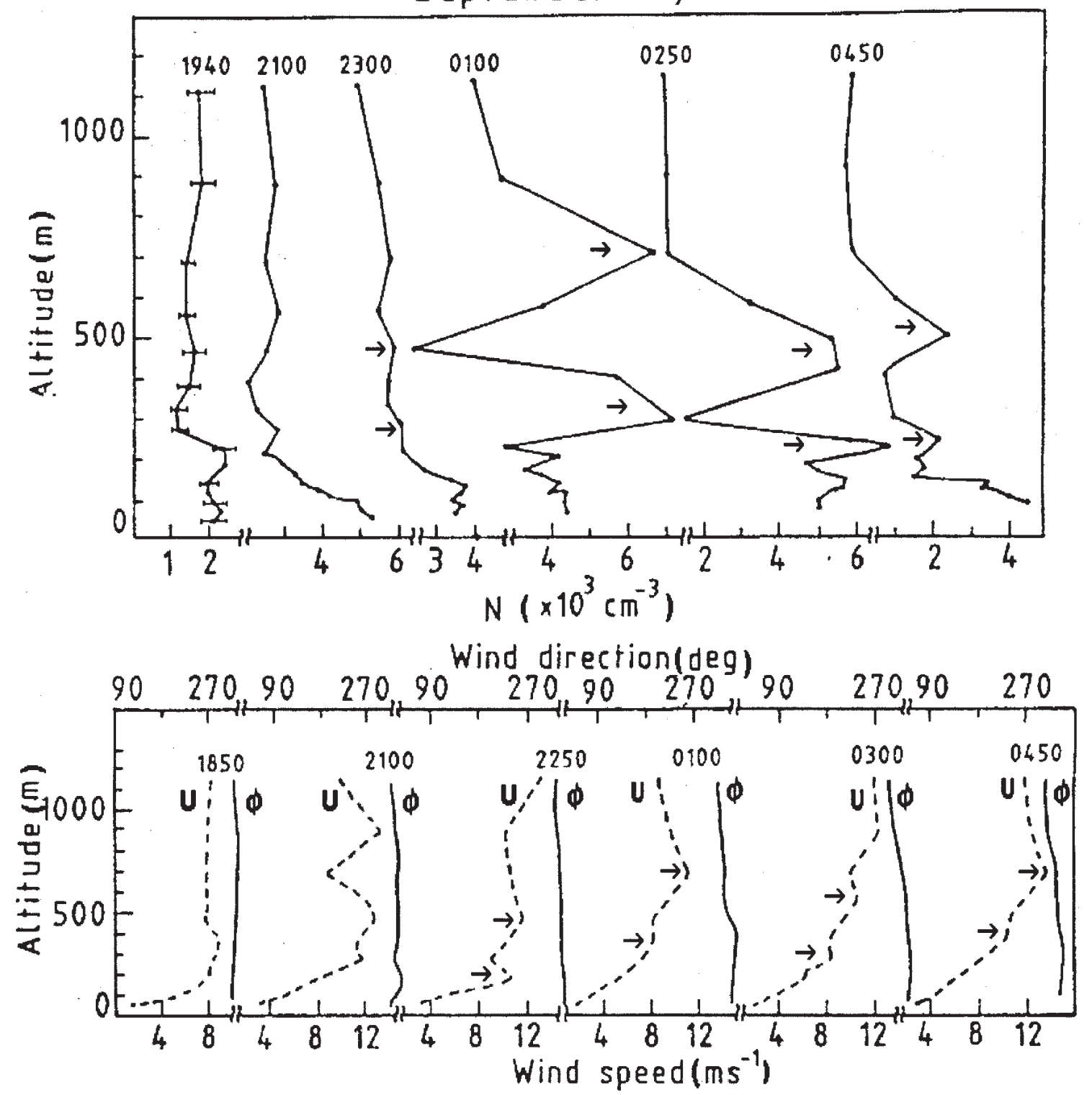

Figure 17. Aerosol stratification associated with wind shears in the nocturnal mixing region on 19th September 1999; altitude profiles of $N$ at different times during the night (a), and altitude profiles of wind speed and direction obtained using a pilot balloon (b).

context. The general shape of the altitude profile observed in the early night hours continue to persist up to $\sim 2300$ IST i.e $\sim 4-5$ hrs. after the sunset. A correlation analysis of wind speed at different times of the day with $N$ at $\sim 2000$ IST also revealed (Parameswaran and Vijayakumar 1994b) that correlation is maximum with wind speed $5 \mathrm{hrs}$ before the lidar observation time. This is because of the fact that even though the generation of eddies ceases soon after the sunset, eddies generated in the afternoon hours continues to persist in the atmosphere for a few hours even after the sunset (Delage 1974; Benkley and Schulman 1979). The altitude structure of $N$ observed in the early night hours thus is the remnant of the altitude structure that existed during the afternoon period.
Figure 17 shows a sequence of the altitude profile of $N$ along with $U$ for 19th September 1990 to depict the temporal development of nocturnal structure in $N$. Altitude profiles of $U$ and $\phi$ are obtained by tracking the pilot balloons launched during lidar observations. In the late night hours the altitude distribution is mainly governed by the altitude structure of $U$. The first three profiles in the early night hours are almost similar and not significantly influenced by the wind profile. The post-midnight profiles of $N$ show aerosol stratifications, which are much above the standard error associated with $N$ (typical errors are illustrated by horizontal bars in the first profile). Altitudes of these stratified layers match fairly well with the low wind shear regions (peaks in $U$ profile) marked by 
arrows in figure 17. A detailed study (Rajeev and Parameswaran 1995) of $N$ and atmospheric stability has shown that aerosol stratification associated with stratified turbulence is fairly common during the late night hours (Parameswaran et al 1997b). Accretion of aerosols occurs in a stable region sandwiched between two unstable (turbulent) regions and depletion of aerosols occurs in a turbulent zone embedded in the stable region. The stratification of aerosols at regions where the wind shear is small is evident from figure 17 .

\section{Summary}

Systematic studies of the characteristics of aerosols in the atmospheric mixing region at the tropical coastal station Trivandrum has brought out the following features

- Altitude structure of aerosol number density in ABL shows a fairly well-mixed region below $\sim 400 \mathrm{~m}$. At the top of this region a capped aerosol layer is observed. This upper altitude limit of the well-mixed region is termed as the aerosol mixing height, which is linked fairly well with the altitude of TIBL.

- Above the mixing height where the aerosol concentration decreases rather slowly with increase in altitude is the entrainment region.

- The altitude variation above aerosol mixing height can be fairly well represented by an exponentially decreasing function of altitude. The scale height parameter representing this decrease is in the range $500-1500 \mathrm{~m}$.

- The aerosol mixing height generally lies in the range 150-400 $\mathrm{m}$ and shows systematic seasonal variation with three maxima; one each during the dry months of March and November and the third during the S-W monsoon period. While the increased mixing height during the dry months can be explained on the basis of increased convective activity in ABL, the increase in aerosol mixing height during the $\mathrm{S}-\mathrm{W}$ monsoon period can be attributed to increase in mechanical mixing caused by wind shears.

- The seasonal variation of mixing region aerosol optical depth show two maxima, one in February and the other during the S-W monsoon period. This pattern is different from the seasonal pattern observed in columnar optical depth (maximum during April-May and minimum during the S-W monsoon). The monsoon peak is relatively strong below $100 \mathrm{~m}$ and the winter peak becomes prominent at higher altitudes in the mixing region

- Aerosol number density (or equivalently the extinction) shows a non-linear dependence on sea-breeze strength $(U)$. It can either be represented by a relation $N=N_{0} \exp (b U)$ with $0.06<b<0.14$ or $N=N_{b}+C U^{d}$ with $\mathrm{d} \sim 2.94$ below $h_{m}$ and 3.45 above $h_{m}, N_{b}$ representing the sea-breeze independent background component. Seasonal variation of $N_{b}$ shows two maxima, one during the winter months and the other during the S-W monsoon. The former peak is weak in lower altitude and increases with increase in altitude. The latter peak is more significant at lower altitudes and decreases with increase in altitude.

- Contribution of mixing region to columnar aerosol optical depth shows variation with season. This contribution is high during winter and $\mathrm{S}-\mathrm{W}$ monsoon months and minimum in summer and autumnal months. This can be explained on the basis of the seasonal changes in the strength of vertical transport in the ABL.

- The AOD data during the period 1989-97 shows an increasing trend from 1989 to 1997 both in the mixing region and aloft. The rate of increase is more pronounced at higher altitudes.

- Convectively dominated daytime altitude structure of aerosols in ABL continues to persist for 4-5 hrs after the sunset. During the late night hours the altitude distribution is significantly governed by the prevailing wind profile.

- Accretion of aerosols occurs in stable regions sandwiched between two turbulent regions and depletion of aerosols occurs in turbulent pockets in an otherwise stable region.

\section{Acknowledgements}

The author thanks the Meteorological facility TERLS for providing the surface meteorological data used for this study and India Meteorology Department for providing the radiosonde data. Thanks are also due to Dr. K Krishnamoorthy, Dr. G Vijayakumar, Dr. K Rajeev, Dr. S K Satheesh Mr. P Pradeepkumar and Ms Rekha Rajan who were associated with the author at different stages of this study and also for their involvement in conducting the CW Lidar observations and data analysis. The author is grateful to Dr. P K Kunhikrishnan and Dr. K Sengupta for the valuable discussions the author had with them in the course of this study regarding the ABL features and also for providing the sodar and ABL data used for this study.

\section{References}

Benkley C W and Schulman L L 1979 Estimating hourly mixing depths from historical meteorological data; $J$. Appl. Meteorol. 18 772-780

Charlson R J, Schwartz S E, Hales J M, Can R D, Coaldey J A Jr, Hansen J E and Hofmann D J 1992 Climate forcing by anthropogenic aerosols; Science 255 423-430 
Coakley J A, Can R D, Yunevich F B 1983 The effect of tropospheric aerosols on the earths radiation budget: A parameterisation for climate models; J. Atmos. Sci. $\mathbf{4 0}$ $116-138$

Coulter R L 1979 A comparison of three methods of measuring mixing layer height; J. Appl. Meteorol. 18 1495-1499

Delage Y 1974 A numerical study of the nocturnal atmospheric boundary layer; Q. J. R. Meteor. Soc. 100 351-364

Devara P C S and Ernet Raj E 1993 Lidar measurements of aerosols in the tropical atmosphere; Adv. Atmos. Sci. 10 365-378

Devara P C S, Raj P E, Pandithurai G, Mahesh Kumar R S and Dani K K 1997 Advances in atmospheric hydro graphic and vegetation remote sensing with lidar; $J$ Indian Society of remote scanning 25 225-238

Devara P C S, Pandithurai P E, Raj R S, Maheshkumar K K, Dani 1998 Atmospheric aerosols - cloud - stability relationship as observed with optical and radio remote sensing technique; Atmos. Res. 40 65-76

Exton H J, Laltan J, Park P M, Perry S J, Smith M N and Allen R B 1985 The production and dispersal of Marine aerosol; Q. J. R. Meteorol. Soc. $111817-837$

Kaimal J C and Finnigan J J 1994 The atmospheric boundary layer flows - Their structure and measurements (Oxford: Oxford University Press)

Krishnamoorthy K, Prabha R, Nair and Krishna Murthy B V 1991 Size distribution of coastal aerosols: effects of local sources and sinks; J. Appl. Meteorol. 30 844-852

Krishnamoorthy K, Krishna Murthy B V and Prabha R Nair 1993 Sea-breeze front effects on boundary layer aerosols at a tropical coastal station; J. Appl. Meteorol. 32 1196-1205

Krishnamoorthy K, Niranjan K, Narasimhamoorthy B, Agashe V V and Krishnamoorthy B V 1999 Aerosol climatology over India 1-ISRO GBP MWR and data baseISRO GBP SR 03 99; Indian Space Research Organisation, Bangalore.

Kunhikrishnan P K 1990 Studies of atmospheric boundary layer; Ph D Thesis, University of Kerala, Trivandrum, India

Kunhikrishnan P K, Narayanan Nair K, Sen Gupta K, Radhika Ramachandran and Prakash T W J 1990 Sodar echo pattern and study of thermal plumes over Thumba Mausam 41 583-588

Lal M, Cubasch U, Voss R and Waszkewitz J 1995 Effect of transient increase in green house gases and sulphate aerosols on monsoon climate; Curr Sci 69 752-762

McClatchey R A, Fenn R W, Selby J E A Volz F E and Garing J S 1972 Optical properties of atmosphere AFGRL72-0497; U S Air Force Geophysical Laboratory Hanscom AFB Massachusetts USA.

Monahan E C, Fairall C W, Davidson K L and Boyle P J 1983 Observed inter relations between $10 \mathrm{~m}$ winds ocean white caps and marine aerosols; Quart. J. R. Meteorol. Soc. 109 379-392

Parameswaran K, Rose K O and Krishna Murthy B V 1984 Aerosol characteristics from bistatic lidar observations; $J$. Geophys Res 89 2541-2552

Parameswaran K, Krishna Murthy B V, Rose K O, Satyanarayana M 1993 Lidar studies of tropospheric aerosol extinction and estimation of vertical eddy diffusion coefficient at a tropical station; Annals Geophys 11 61-67

Parameswaran K and Vijayakumar G 1994a Effect of atmos- pheric relative humidity on aerosol size distribution; Indian J. Rad. Space Phys 23 175-188

Parameswaran K and Vijayakumar G 1994b Study of mixing region aerosols over a tropical coastal station global change studies ISRO-GBP- 42-94; Indian Space Research Organisation, Dept of Space, Bangalore 73-85

Parameswaran K, Vijayakumar G, Krishna Murthy B V and Krishna Moorthy K 1995 Effect of wind speed on mixing region aerosol concentration at a tropical coastal station; J. Appl. Meteorol. 34 1392-1397

Parameswaran K 1996 Effect of relative humidity on light scattering by poly disperse aerosol; Indian J. Rad. Space Phys. 25 64-73

Parameswaran K, Vijayakumar G and Krishna Murthy B V 1997a Lidar observations on aerosol mixing height in a tropical coastal environment; Indian J. Rad. Space Phys. 26 15-21

Parameswaran K, Rajeev K and Sen Gupta K 1997b An observational study of night time aerosol concentration in the lower atmosphere at a tropical coastal station; $J$. Atmos. Terr. Phys 59 1727-1737

Parameswaran K, Rekha Rajan, Vijayakumar G, Rajeev K, Krishna Moorthy K, Prabha R Nair and Satheesh S K 1998 Seasonal and long term variations of aerosol content in the atmospheric mixing region at a tropical station on the Arabian Sea coast; J. Atmos. Terr. Phys. 60 17-25

Parameswaran K, Prabha R Nair, Rekha Rajan and Balasubrahamanyan D 2001 Spatial distribution of aerosol concentration over the Arabian Sea and the Indian Ocean during IFP of INDOEX; Curr Sci 80 161-170

Prakash J W J, Radhika R, Narayanan Nair K, Sen Gupta K and Kunhikrishnan P K 1993 On the spectral behaviour of atmospheric boundary layer parameters at Thumba India Q. J. R. Meteorol. Soc. 119 187-197

Rajeev K and Parameswaran K 1995 Altitude structure of aerosols in the nocturnal mixing region; Proc Of IASTA Conference, Physical Research Laboratory Ahmedabad $22-25$

Rajeev K, Ramanathan V and Meywerk 2000 J Regional aerosol distribution and its long-range transport over Indian Ocean; J. Geophys. Res. 105 2029-2043.

Rao Y P South west monsoon 1976 Meteorological Monograph Synoptic Meteorology No 1/1976 IMD India

Rekha R 2001 Boundary layer aerosol characteristics at a tropical coastal station Trivandrum from lidar and impactor measurements; Ph.D thesis Mahatma Gandhi University, Kerala

Sasano Y, Shigematsu A, Shimizu M, Takuchi N and Okuda M 1982 On the relationship between the aerosol layer height and the mixed layer height determined by lower radar over low level radiosonde observations; J. Meteorol. Soc. Japan 60 889-895

Schwartz S E 1996 The white house effect - short wave radiation forcing of climate by anthropogenic aerosols: An overview; J. Aero. Sci. 27 359-382

Sen Gupta K and Radhika Ramachandran 1998 Tropical atmospheric boundary layer; Proc. Indian Nat. Sci. Aca. 64A $267-276$

Sunil T 1997 Study of coastal atmospheric boundary layer; Ph D Thesis University of Kerala, Trivandrum p 125

Vijayakumar G, Parameswaran K and Rekha Rajan R 1998 Aerosols in the atmospheric boundary layer and its association with surface wind speed at a coastal site; $J$. Atmos. Sol. Terr. Phys. $601531-1542$ 